Check for updates

Cite this: RSC Adv., 2018, 8, 34491

Received 13th July 2018

Accepted 26th September 2018

DOI: $10.1039 / c 8 r a 05969 a$

rsc.li/rsc-advances

\section{Solventless, selective and catalytic oxidation of primary, secondary and benzylic alcohols by a Merrifield resin supported molybdenum(vı) complex with $\mathrm{H}_{2} \mathrm{O}_{2}$ as an oxidant $\uparrow$}

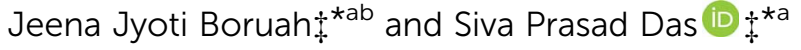

Here, we have described the synthesis, characterization and catalytic activity of a dioxo-molybdenum(VI) complex supported on functionalized Merrifield resin (MR-SB-Mo). The functionalization of Merrifield resin (MR) was achieved in two-steps viz. carbonylation (MR-C) and Schiff base formation (MR-SB). The compounds, MR-C, MR-SB and MR-SB-Mo, were characterized at each step of the synthesis by elemental, SEM, EDX, thermal, BET and different spectroscopic analysis. The catalyst, MR-SB-Mo, efficiently and selectively oxidized a wide variety of alcohols to aldehydes or ketones using $30 \% \mathrm{H}_{2} \mathrm{O}_{2}$ as an oxidant with reasonably good TOF $\left(660 \mathrm{~h}^{-1}\right.$ in case of benzyl alcohol). The catalyst acted heterogeneously under solventless reaction conditions and did not lead to over oxidized products under optimized conditions. The catalyst afforded regeneration and can be reused for at least five reaction cycles without loss of efficiency and product selectivity. A reaction mechanism for the catalytic activity of MR-SB-Mo was proposed and a probable reactive intermediate species isolated.
\end{abstract}

\section{Introduction}

The catalytic oxidation of alcohols is a basic transformation reaction, in synthetic organic chemistry in particular, used in the chemical and pharmaceutical industries, where aldehydes find wide application. ${ }^{1}$ Besides these, biologically the oxidation of alcohol to carbonyl offers a good contribution towards the degradation of fats during metabolism in humans (e.g. L-malate to oxaloacetate) which is part of the citric acid cycle. ${ }^{2}$ Due to the presence of a carbonyl group as an intermediate and final product in several natural products, ${ }^{\mathbf{1}}$ fine chemicals ${ }^{\mathbf{1}}$ and medicinally important components, ${ }^{1}$ there has been an upsurging interest in developing a variety of reagents and catalytic systems which has led to an improvement in the economic and environmentally benign synthetic methodology.

Traditional protocol for the oxidation of alcohol carried out by using stoichiometric inorganic oxidant such as permanganate, bromate, or $\mathrm{Cr}(\mathrm{vI})$ based reagents ${ }^{3}$ suffer from drawback

\footnotetext{
${ }^{a}$ Department of Chemistry, School of Science, RK University, Bhavnagar Highway, Kasturbadham, Rajkot-360020, Gujarat, India. E-mail: siva.spd@gmail.com; siva. das@rku.ac.in; jeena.jyoti@gmail.com; jeena.jyoti@rku.ac.in; Tel: +91-9678084296 ${ }^{b}$ Department of Chemistry, Moridhal College, Moridhal, Dhemaji-787057, Assam, India

$\dagger$ Electronic supplementary information (ESI) available: $\mathrm{N}_{2}$ adsorption-desorption isotherms, IR spectra of the isolated peroxomolybdate(vI) intermediate, comparison table, and detailed synthetic procedure and characterization of SB-Mo. See DOI: 10.1039/c8ra05969a

\$ Both the authors contributed equally to this work.
}

such as large amount of heavy metal waste, generation of toxic by-products, difficulty in work up and requirement of larger amount of oxidizing agents., ${ }^{3,4}$ Moreover, in some cases, the oxidation reactions are performed under severe reaction conditions, such as high temperature and high oxygen pressure, in presence of environmentally undesired solvents, typically chlorinated hydrocarbons which are very toxic, corrosive and environmentally hazardous. ${ }^{3,4 a, 5}$ Therefore, search for alternative environmentally benign and safe protocols for the synthesis of different organic carbonyl compounds and their derivatives by alcohol oxidation continues unabated.

Although myriads of traditional user-friendly oxygen sources such as molecular oxygen, hydrogen peroxide, tert-butylhydroperoxide (TBHP) are used to eradicate such harmful waste for alcohol oxidation, ${ }^{5}$ but aqueous $\mathrm{H}_{2} \mathrm{O}_{2}$ constitutes a clean, waste avoiding, potentially green, and environmental-friendly ideal oxidant due to its cost effectiveness, easy availability, ecologically acceptable and it generates only water as the by-product. ${ }^{6}$ Also, the reaction parameters can be highly tuned by using $\mathrm{H}_{2} \mathrm{O}_{2}$ which play a vital role in oxidation reaction. We foresee that $\mathrm{H}_{2} \mathrm{O}_{2}$ and $\mathrm{O}_{2}$ (or air) will be complementary useful clean oxidants in practical chemical synthesis. Though molecular oxygen is an ideal oxidant, however, aerial oxidation has one or more of the major impacts such as difficult to control which result combustion and occasionally the reaction should have to be performed with a low conversion to circumvent from over oxidation limit their synthetic applications. ${ }^{6 a}$ Besides these, although both the oxygen atom present in $\mathrm{O}_{2}$ may be employed for oxidation to meet the 
metrices for measuring the 'greenness' i.e. $100 \%$ atom efficiency, but in most of the reactions, only one oxygen atom is used and show only $50 \%$ atom efficiency, consequently to meet the requirement, the oxidation reactions often need certain reducing agents to arrest the extra oxygen atom during the reaction. ${ }^{6 a, 7}$ The rate of oxidation towards $\mathrm{H}_{2} \mathrm{O}_{2}$ induced oxidation reaction including sulfide, olefin and alcohol oxidation is relatively slow or negligible owing to its weak oxidative nature and as a consequence, it has to be activated by using a suitable catalysts. ${ }^{\mathbf{b}, \mathbf{6} b, \boldsymbol{8}}$ As a result, immense number of transition metal based catalytic systems such as vanadium, ${ }^{\mathbf{9}}$ osmium, ${ }^{\mathbf{1 0}}$ palladium, ${ }^{11}$ ruthenium, ${ }^{12}$

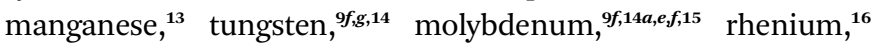
cobalt, ${ }^{11 c, 17}$ copper, ${ }^{11 c, 18}$ and iron ${ }^{19}$ have been developed towards oxidation of alcohols. Though the transition metal ion complexes are reported to have their catalytic activity with high selectivity, good efficiency and reproducibility, however several catalytic processes associate with one or more of the disadvantages such as requirement of additives, use of halogenated solvents, homogeneous in nature, production of huge waste materials, corrosion to the industrial materials and some of them are deposited on the reactor wall as well as disrupting the environmental and ecological stability. These shortcomings are fetching increasingly conspicuous in the light of growing ecological awareness in recent years. ${ }^{20}$ Interestingly, over the recent years, a new class of catalyst has been developed which utilizes light for alcohol oxidation. ${ }^{21}$ These photocatalysts absorbs light (visible or UV) and coming under "Greener" approaches. However, majority of these protocols also suffered from drawbacks of the requirement of organic solvents and higher reaction time.

Therefore, constructing a safer, efficient and highly selective heterogeneous catalyst towards alcohol oxidation with $\mathrm{H}_{2} \mathrm{O}_{2}$ as the oxidant is considered to be the better choice. Apart from these, heterogenization of homogeneous catalysts ${ }^{22}$ by immobilization of active soluble catalysts on insoluble polymeric matrix offers improved stability, increased product selectivity, easy separation and recycling to the precious metal complexes. $^{22 a, 23}$ In this regard, the use of Merrifield resin, which is a chloromethylated polystyrene cross-linked with divinyl benzene ${ }^{24}$ is quite reasonable as the resin is readily availability, easy to handle, cheap, mechanically and chemically robust and most importantly able to undergo facile functionalization as well as provide high-loading capacity. ${ }^{23 a, 25}$

Keeping these facts into our account, we presented here the synthesis and characterization of a Merrifield resin supported dioxomolybdenum(vi) compound which acts as a heterogenous catalyst for the efficient and selective oxidation of alcohols to aldehydes or ketones. Interestingly, the protocol worked under solventless conditions with aqueous $\mathrm{H}_{2} \mathrm{O}_{2}$ as an oxidant and achieved the product selectivity with a wide range of substrates viz. primary, secondary and benzylic alcohols.

\section{Experimental}

\subsection{Materials}

The source of chemicals are given below: Merrifield resin (2\% crosslinked, 2-4 mmol Cl per $\mathrm{g}$ of polymeric support), tetraethylammoniumchloride, 2-(aminomethyl)pyridine, 4-fluorobenzyl alcohol, 4-chlorobenzyl alcohol, 4-bromobenzyl alcohol, 4methoxybenzyl alcohol, 4-hydroxybenzyl alcohol, diphenylmethanol, 1-phenylethanol, borneol, 2-octanol, 2-ethyl-1-hexanol, 1butanol (Alfa Aesar, Mumbai, India), hydrogen peroxide (30\%, $50 \%$ and $6 \%$ ), sodium bicarbonate, dimethyl sulfoxide (DMSO), tetrahydrofurane (THF), methanol (MeOH), benzyl alcohol, 4nitrobenzyl alcohol, cyclohexanol, cyclopentanol, menthol, 2butanol, 1-octanol, 1-pentanol, 1-decanol (S D Fine-Chem Limited, Mumbai, India), silica gel (60-120 mesh) (Molychem, Mumbai, India). TLC plates (TLC Silica gel $60 \mathrm{~F}_{254}$ ) were purchased from Merck Limited (India). $\left[\mathrm{MoO}_{2}(\mathrm{acac})_{2}\right]$ was prepared by following a reported procedure. ${ }^{26}$ The other reagents and solvents were of commercially available reagent quality, unless otherwise stated.

\subsection{Physical measurements}

Elemental analysis of the compounds for $\mathrm{C}, \mathrm{H}$ and $\mathrm{N}$ were carried out with the help of Perkin-Elmer 2400 series II CHN analyzer. The molybdenum content was determined by using atomic absorption spectroscopy (Thermo iCE 3000 series Atomic absorption spectrophotometer model analyst 200) and EDX analysis. Chlorine content was determined by EDX analysis. C, H and $\mathrm{N}$ content were also determined with the help of EDX analysis. IR spectra of the compounds were recorded in $\mathrm{KBr}$ pellet (4000-400 $\mathrm{cm}^{-1}$ ) using a Nicolet model 410 FTIR spectrophotometer. The UV-visible diffuse reflectance analysis of the samples were carried out with the help of a Hitachi U-3400 spectrophotometer equipped with an integrating sphere of $60 \mathrm{~mm}$ inner diameter using spectroscopic grade $\mathrm{BaSO}_{4}$ as a reference in the range of $240-800 \mathrm{~nm}$. The SEM images of the samples were recorded by using the JEOL JSM-6390LV Scanning Electron Micrograph with an attached energy-dispersive X-ray detector. The dinitrogen adsorption/desorption measurements were carried out on a Quantachrome model Nova 4200e porosimeter at $77.3 \mathrm{~K}$. The thermogravimetric analysis of the samples was done by using a SHIMADZU TGA-50 system under an atmosphere of nitrogen using an aluminium pan at a heating rate of $10^{\circ} \mathrm{C} \mathrm{min}^{-1}$. The powder X-ray diffraction (XRD) patterns were carried out by a Rigaku X-ray diffractometer (Miniflax, UK) using $\mathrm{Cu} \mathrm{K} \alpha(\lambda=0.154 \mathrm{~nm})$ radiation over the $2 \theta$ range of $10-70^{\circ}$. The XPS measurements were conducted in a multi-probe system (Omicron Nanotechnology, Germany) equipped with a dual $\mathrm{Mg}$ / Al X-ray source and a hemispherical analyzer operating in constant analyzer energy (CAE) mode. The X-ray source $(\mathrm{Mg} \mathrm{K} \alpha)$ was operated at $15 \mathrm{kV}$ and $300 \mathrm{~W}$. Charging effects were corrected by setting the binding energies of the adventitious $\mathrm{C}$ ls line at $284.8 \mathrm{eV}$. GC analysis was carried out on a CIC, Gas Chromatograph model 2010 using a SE-52 packed column (length $2 \mathrm{~m}, 1 / 8^{\prime \prime}$ OD) with a Flame Ionization Detector (FID), and nitrogen as the carrier gas (30 $\left.\mathrm{mL} \mathrm{min}^{-1}\right)$. The ${ }^{1} \mathrm{H}$ NMR spectra of the substrates were recorded with the help of Bruker, AVANCE $400 \mathrm{MHz}$ spectrophotometer in $\mathrm{CDCl}_{3}$. Tetramethylsilane (TMS) or residual solvent peak was used as an internal standard.

\subsection{Functionalization of the Merrifield resin (MR)}

2.3.1 Carbonyl functionalization of the MR (MR-C). The MR was carbonyl functionalized by following a reported 
procedure with some modification. ${ }^{27}$ In the process, the MR was initially pre-swell in DMSO-THF $(5: 1)$ for $24 \mathrm{~h}$ at room temperature. Subsequently, the carbonyl functionalized polystyrene, MR-C was synthesized by mixing $1.0 \mathrm{~g}$ of MR with $0.50 \mathrm{~g}, 5.95 \mathrm{mmol}$ sodium bicarbonate $\left(\mathrm{NaHCO}_{3}\right)$ in $50 \mathrm{~mL}$ DMSO under reflux for $24 \mathrm{~h}$. After cooling, the resultant polymer was filtered off, washed with water $(3 \times 10 \mathrm{~mL})$ and methanol $(3$ $\times 10 \mathrm{~mL}$ ), then dried under high vacuum.

2.3.2 Synthesis of the Merrifield resin Schiff base support (MR-SB). The Merrifield resin supported Schiff base was prepared by mixing MR-C with 2-(aminomethyl)pyridine in methanol. In the typical procedure, the MR-C (1.0 g) was preswell in $25 \mathrm{~mL} \mathrm{MeOH}$ for $24 \mathrm{~h}$ at room temperature. Subsequently, $0.36 \mathrm{~g}, 3.32 \mathrm{mmol}$ of 2-(aminomethyl)pyridine (1.5 equiv. of loaded carbonyl group) was added and refluxed the mixture for $48 \mathrm{~h}$. The polymeric beads were slightly darkened from off-white color. After cooling, the solid was filtered off, washed several times by minimum amount of methanol, and then dried under high vacuum.

\subsection{Synthesis of the Merrifield resin supported molybdenum(vi) complex (MR-SB-Mo)}

The supported molybdenum(vi) complex was synthesized by reacting the MR-SB, and $\mathbf{M o O}_{2}(\text { acac })_{2}$ in $\mathbf{M e O H}-\mathrm{THF}(1: 1)$ under reflux condition. In the typical procedure, $1.0 \mathrm{~g}$ of MR-SB was swallowed in $25 \mathrm{~mL} \mathrm{MeOH-THF}(1: 1)$ for $24 \mathrm{~h}$ at room temperature. Subsequently, $0.82 \mathrm{~g}, 2.51 \mathrm{mmol}$ of $\mathrm{MoO}_{2}(\mathrm{acac})_{2}$ (1.5 equiv. of Schiff base loading) and $1.66 \mathrm{~g}, 10.02 \mathrm{mmol}$ of tetraethylammoniumchloride $\left(\mathrm{Et}_{4} \mathrm{NCl}, 6\right.$ equiv. of Schiff base loading) in $5 \mathrm{~mL} \mathrm{MeOH}$ was added and stirred the reaction mixture under reflux for $36 \mathrm{~h}$. The reaction mixture was filtered and the solid was washed with $\mathrm{MeOH}(5 \times 10 \mathrm{~mL})$. The slightly brownish solid products were dried under high vacuum for $6 \mathrm{~h}$ and stored in dry place.

\subsection{Catalytic activity of MR-SB-Mo}

2.5.1 General procedure for oxidation of alcohols to aldehydes or ketones. In the typical procedure, $2.5 \mathrm{mmol}$ of the substrate (alcohol) was added to a $25 \mathrm{~mL}$ round bottom flask containing $2.75 \mathrm{mmol}$ of $30 \%$ aqueous $\mathrm{H}_{2} \mathrm{O}_{2}$ and $5.6 \mathrm{mg}$ of MRSB-Mo (contain $0.0025 \mathrm{mmol}$ of $\mathrm{Mo}$ ). This maintained molar ratio of substrate $: \mathrm{H}_{2} \mathrm{O}_{2}: \mathrm{Mo}=1000: 1100: 1$. The reaction mixture was stirred at $65{ }^{\circ} \mathrm{C}$ and progress was monitored by TLC and GC. After completion of the reaction, the solid catalyst was separated by filtration and the crude filtrate was extracted with ethyl acetate $(3 \times 5 \mathrm{~mL})$. The combined extract was dried over anhydrous magnesium sulfate, filtered and removed the excess ethyl acetate under reduced pressure. This followed by column chromatography of the crude product on silica gel. The pure products were subjected to ${ }^{1} \mathrm{H}$ NMR analysis for identification.

2.5.2 Recyclability of the catalyst. The recyclability of MRSB-Mo was studied by using benzyl alcohol as substrate. In the typical procedure, after completion of the reaction (as mentioned above) the solid catalyst was separated from the spent reaction mixture by filtration, washed with acetonitrile (3 $\times 5 \mathrm{~mL}$ ) and dried in vacuo. The dried catalyst was then added to a fresh lot of reaction mixture maintain molar ratio of substrate : $\mathrm{H}_{2} \mathrm{O}_{2}:$ Mo at $1000: 1100: 1$. The progress of the reaction was monitored by TLC and GC. After completion, the process was repeated so on for upto fifth reaction cycle.

\section{Results and discussion}

\subsection{Synthesis}

The synthetic pathway for the synthesis of the polymersupported molybdenum(vi) compound, MR-SB-Mo is shown in Scheme 1. The carbonyl functionalization of MR to form MR-C was achieved by adopting a previously reported procedure. ${ }^{27} \mathrm{In}$ the next step, the carbonyl group of MR-C was condensed with 2-aminomethylpyridine under reflux condition in methanol to form MR-SB. The molybdenum complex was formed by refluxing MR-SB, $\mathrm{Et}_{4} \mathrm{NCl}$ and $\mathrm{MoO}_{2}(\mathrm{acac})_{2}$ in $\mathrm{MeOH}-\mathrm{THF}(1: 1)$ for $36 \mathrm{~h}$. The $\mathrm{Et}_{4} \mathrm{NCl}$ provides the counter anion required for the formation of the molybdenum(vi) complex. In order to maximized the molybdenum loading, a series of reactions conducted under different reaction condition such as variation of solvent, reaction temperature and time, molar ratio of molybdenum : Schiff base, etc. The experiments revealed that 1.5 equivalent of $\mathrm{MoO}_{2}(\mathrm{acac})_{2}$ with respect to Schiff base loading, MeOH/THF as solvent, under reflux condition and reaction time of $36 \mathrm{~h}$ were optimum for giving maximum molybdenum loading on MR-SB-Mo.

\subsection{Characterization}

The elemental analysis data for the compounds at each step of functionalization are shown below in Table 1. It is seen from the table that the compound MR-SB showed $4.68 \%$ of nitrogen which were absent in MR or MR-C. This indicates the formation of Schiff base by the reaction of carbonyl group of MR-C and 2-

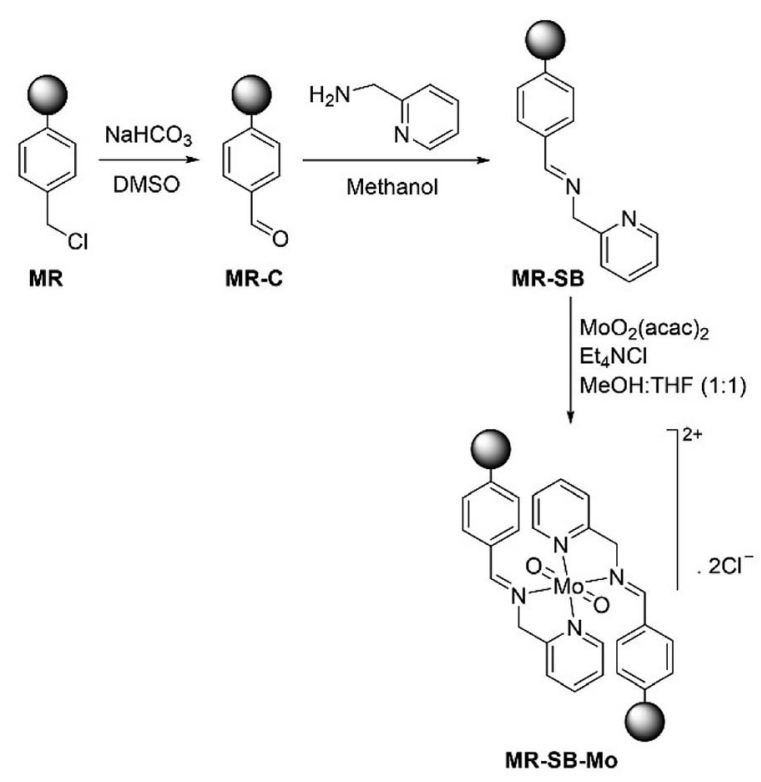

Scheme 1 Synthesis of MR-SB-Mo. " $Q$ " represents polymeric support. 
Table 1 Chemical composition data for MR, MR-C, MR-SB and MR-SB-Mo

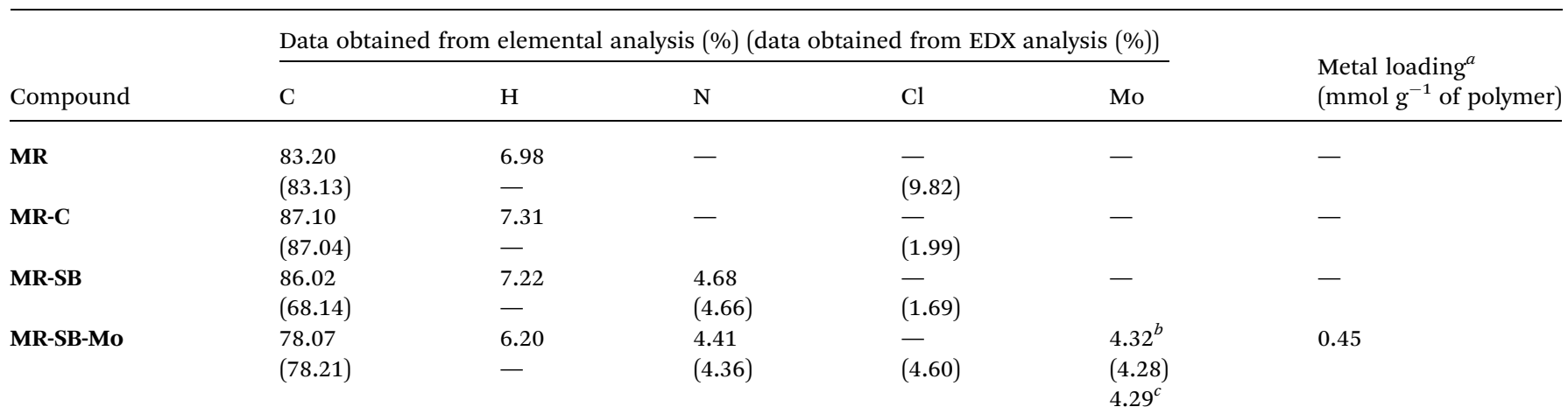

${ }_{c}^{a}$ Metal loading $=($ Observed molybdenum $\% \times 10) /($ atomic weight of molybdenum $) .{ }^{b}$ Data obtained from AAS. “-” stands for not determined.

${ }^{c}$ Molybdenum content determined by AAS after $5^{\text {th }}$ reaction cycle.

aminomethylpyridine. This corresponds to ligand (i.e., 2-aminomethylpyridine) loading of $1.67 \mathrm{mmol} \mathrm{g}^{-1}$ of the polymer support. The value is consistent with the loss of the chlorine from the MR as evident from EDX analysis. From EDX analysis, it was also found that the amount of chlorine was decreased from $9.82 \%$ to $1.99 \%$ during carbonyl functionalization which indicates that nearly $80 \%$ of the chloromethylated groups were converted to carbonyl group in the process. The molybdenum loading in MR-SB-Mo was found to be $0.45 \mathrm{mmol} \mathrm{g}^{-1}$ of the polymeric support. This indicates that nearly half of the Schiff base ligands were coordinated with molybdenum (as two Schiff base molecules coordinated with one molybdenum center). Besides these, after metal incorporation, the chlorine content was increased from $1.69 \%$ (for MR-SB) to $4.60 \%$ (for MR-SBMo), which is due to the presence of the counter anion, $\mathrm{Cl}^{-}$for charge neutralization as shown in the structure for MR-SB-Mo (Scheme 1). The magnetic susceptibility measurements of MRSB-Mo showed the diamagnetic nature of the compound. This confirmed the +6 oxidation state of molybdenum centers.

The scanning electron micrographs (SEM) of the compounds obtained at different stages in the preparation of MR-SB-Mo are shown in Fig. 1. It is revealed from the micrograph that the virgin polymer beads, MR undergoes striking morphological changes to form MR-SB-Mo. The surface of the smooth and spherical beads of MR became lightly rough after carbonyl functionalization (MR-C, Fig. 1(b)) as well as Schiff base formation (MR-SB, Fig. 1(c)). The even roughening as seen in the images also suggest the uniform covalent functionalization on the surface of the MR beads. However, after molybdenum coordination, randomly oriented depositions were observed causing further roughening on the surface of the polymeric beads (Fig. 1(d)). The EDX spectra of MR-SB-Mo (Fig. 1(e)) showed the presence of carbon, nitrogen, oxygen, chlorine and molybdenum on the support.

The powder XRD patterns of MR, MR-C, MR-SB and MR-SBMo are shown in Fig. 2 and were recorded at $2 \theta$ values between 5 and $70^{\circ}$. A broad peak cantered at $2 \theta$ value of $c a .20^{\circ}$ was observed in pristine MR. This type of diffraction pattern is characteristic for the PS-DVB resin. ${ }^{28}$ Similar to MR, almost identical diffraction patterns were observed in MR-C, MR-SB and MR-SB-Mo. This type of broad peak indicates that the developed catalyst and its precursors, i.e., MR, MR-C and MR-SB are almost amorphous in nature. Moreover, the absence of sharp diffraction peaks in MR-SB-Mo indicated the amorphous nature of the attached $\mathrm{MoO}_{2}{ }^{2-}$ moiety. It is notable that during the synthesis of the MR-SB-Mo via different functionalization steps, there is no change in amorphousness of MR.

In order to gain the electronic properties for the surface of MR-SB-Mo, XPS spectrum of the compound was recorded and presented in Fig. 3. From the figure it is seen that the spectrum
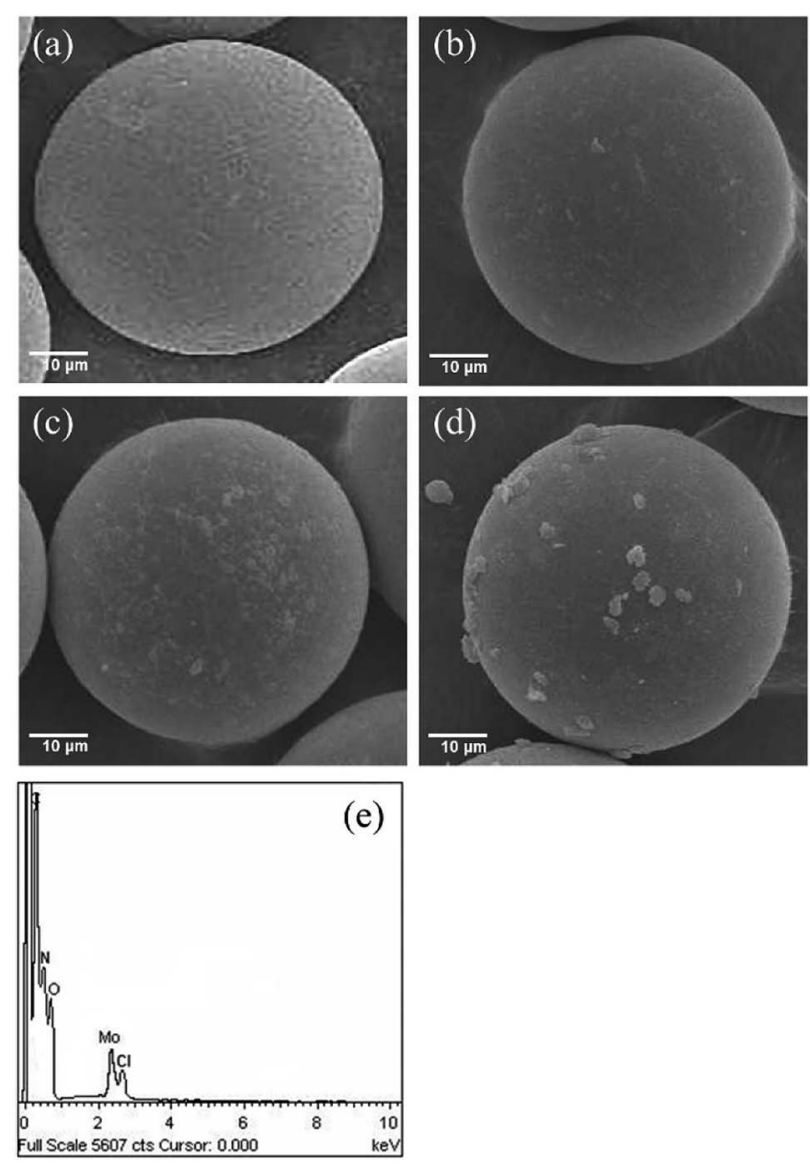

Fig. 1 Scanning electron micrographs of (a) MR, (b) MR-C, (c) MR-SB, and (d) MR-SB-Mo. EDX spectra of (e) MR-SB-Mo. 


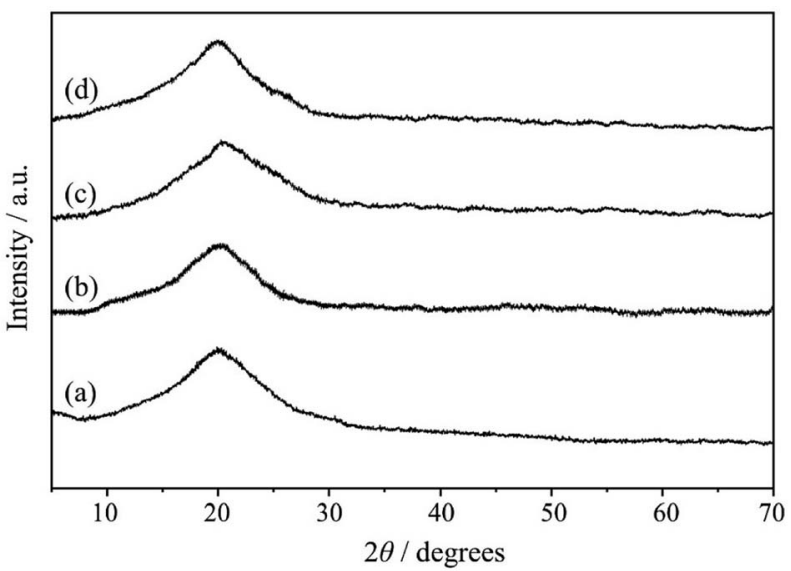

Fig. 2 The XRD patterns of (a) MR, (b) MR-C, (c) MR-SB and (d) MRSB-Mo.

displayed two well resolved peaks at 232.5 and $235.7 \mathrm{eV}$ in the Mo (3d) region. ${ }^{29}$ On the basis of available literature reports, ${ }^{29}$ these peaks correspond to Mo $\left(3 \mathrm{~d}_{3 / 2}\right)$ and Mo $\left(3 \mathrm{~d}_{5 / 2}\right)$, respectively which is attributable to the molybdenum centers in +6 oxidation state, i.e., diamagnetic. This diamagnetic behavior of MR-SB-Mo shown by XPS analysis is in agreement with the results obtained from magnetic susceptibility analysis.

The surface area, pore volume, and pore size of the synthesized compounds viz. MR, MR-C, MR-SB, and MR-SB-Mo, were investigated by $\mathrm{N}_{2}$ absorption and desorption measurements at liquid nitrogen temperature. The surface areas were measured by following the Brunauer-Emmett-Teller (BET) method ${ }^{\mathbf{3 0}}$ and

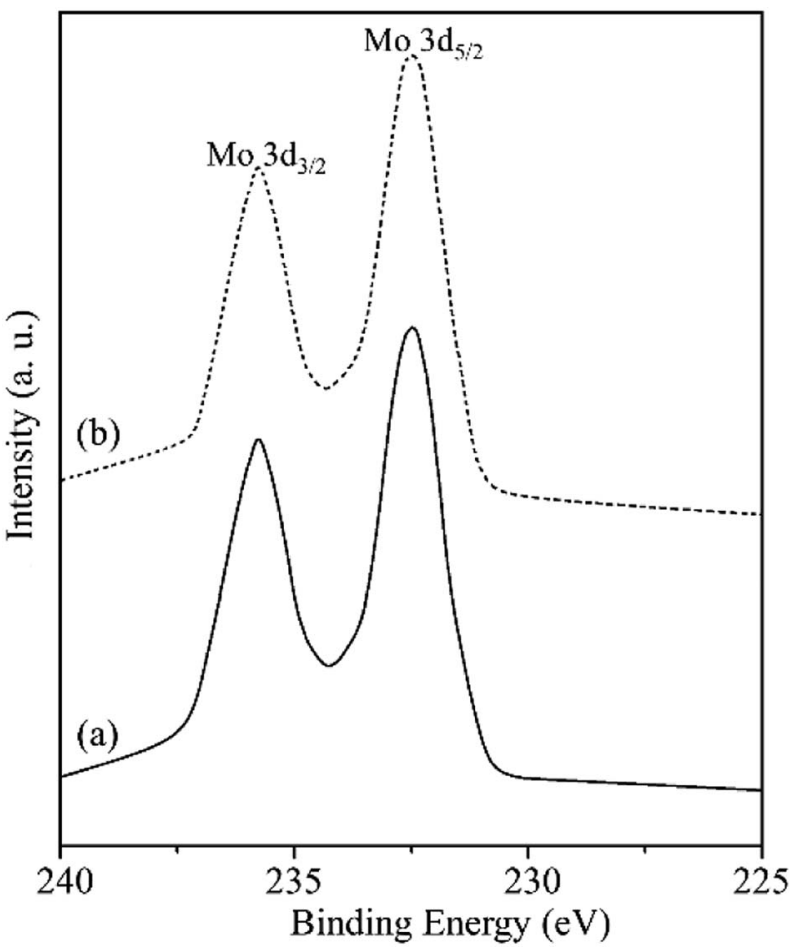

Fig. 3 XPS Mo $\left(3 d_{3 / 2}\right)$ and Mo $\left(3 d_{5 / 2}\right)$ spectra of (a) MR-SB-Mo and (b) MR-SB-Mo after the $5^{\text {th }}$ reaction cycle. the pore volume was determined by following the Barrett-Joyner-Halenda (BJH) model in the nitrogen isotherms. ${ }^{31}$ The data are presented in Table 2 . It is seen from the data that the surface areas, pore volumes and pore radius were decreased with increasing functionalization steps. This is because the functionalization may as well as metal loading blocked the pore of the polymeric beads. Similar types of observation were reported earlier with MR based catalysts. ${ }^{32}$ The nitrogen adsorption/ desorption isotherms showed typical TYPE II adsorption (Fig. S1, ESI $\dagger$ ) of an IUPAC standard ${ }^{33}$ which is the characteristics of macroporous or nonporous material. ${ }^{34}$

Vital information can be derived by comparing the infrared (IR) spectral data for the compounds at each synthetic step. After each synthetic step, characteristic new peaks may appear or shifted to a new position which confirmed the chemical transformations. The FT-IR spectra for the compounds are shown in Fig. 4 and important peaks are assigned in Table 3. On the basis of available reports, the change in intensity of the $\nu(\mathrm{C}-$ $\mathrm{Cl}$ ) peak is found to be the indicator of the functionalization of chloromethyl group. ${ }^{32 a, 35}$ It is evident by comparing the IR spectra of MR and MR-C that the strong peak appeared at $1262 \mathrm{~cm}^{-1}$ in MR which is attributed to $\nu(\mathrm{C}-\mathrm{Cl})^{32 a, 35 a, b}$ was disappeared (or significantly decreased the intensity) after carbonyl functionalization in MR-C. It is pertinent here to mention that after carbonyl functionalization the concentration of chloromethyl group in MR was dropped nearly $80 \%$. Thus, this observation is in consistent with the data obtained from elemental analysis. Besides this, a strong peak appeared at $1728 \mathrm{~cm}^{-1}$ which is due to $\nu(\mathrm{C}=\mathrm{O})$ of the aldehyde group. ${ }^{36}$ Additionally, two new weak intensity peaks appeared for $\nu(\mathrm{C}-$ $\mathrm{H})_{\text {aldehydic }}$ at 2826 and $2721 \mathrm{~cm}^{-1} \cdot{ }^{36 b, c}$ This further confirmed the conversion of chloromethyl group to aldehyde group.

In MR-SB, a new strong peak appeared at $1638 \mathrm{~cm}^{-1}$ which is attributable to $\nu(\mathrm{C}=\mathrm{N})_{\text {imine }}{ }^{36 a, 37}$ However, the peak at $1728 \mathrm{~cm}^{-1}$ due to $\nu(\mathrm{C}=\mathrm{O})$ in MR-C was disappeared in MR-SB. This confirmed the condensation of aldehyde group with the amine group of 2-aminomethylpyridine to form an imine. Additionally, new medium to strong intensity peaks were appeared at $1573(\mathrm{~s}), 609(\mathrm{~m})$, and $408(\mathrm{~m}) \mathrm{cm}^{-1}$ which can be assigned to $\nu(\mathrm{C}=\mathrm{N})_{\text {pyridine, }}$ Py(in-plane ring deformation), and Py(out-of-plane ring deformation), respectively of a pyridine moiety. ${ }^{37,38}$ Thus the IR spectral analysis clearly confirmed the formation of MR-SB as shown in Scheme 1. Interestingly, in MRSB-Mo, new and strong peaks appeared at 964 and $911 \mathrm{~cm}^{-1}$ which were assigned for $\nu(\mathrm{O}=\mathrm{Mo}=\mathrm{O})_{\text {asym }}$ and $\nu(\mathrm{O}=\mathrm{Mo}=$ O) $)_{\text {sym }}$, respectively. ${ }^{39}$ Further the peak due to $\nu(\mathrm{C}=\mathrm{N})_{\text {imine }}$

Table 2 The surface area, pore volume, and pore size of MR, MR-C, MR-SB, and MR-SB-Mo

\begin{tabular}{lcll}
\hline Compound & $S_{\mathrm{BET}}{ }^{a}\left(\mathrm{~m}^{2} \mathrm{~g}^{-1}\right)$ & $V_{\mathrm{tot}^{b}}\left(\mathrm{cc} \mathrm{g}^{-1}\right)$ & Pore radius $(\AA)$ \\
\hline MR & 12.3 & 0.14 & 51.5 \\
MR-C & 7.6 & 0.09 & 30.2 \\
MR-SB & 6.2 & 0.07 & 26.4 \\
MR-SB-Mo & 4.4 & 0.04 & 15.9
\end{tabular}

${ }^{a}$ BET surface area. ${ }^{b}$ Total pore volume. 


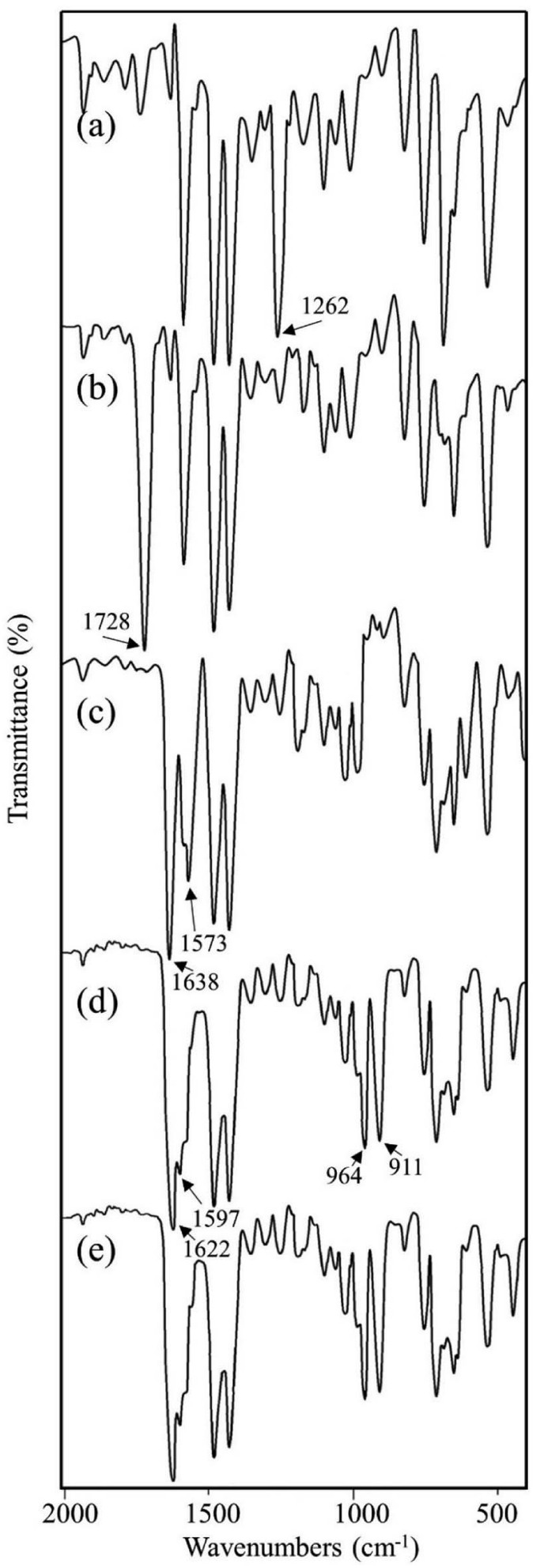

Fig. 4 FTIR spectra for (a) MR, (b) MR-C, (c) MR-SB, (d) MR-SB-Mo, and (e) MR-SB-Mo after $5^{\text {th }}$ reaction cycle.

appeared at $1638 \mathrm{~cm}^{-1}$ of MR-SB was shift to $1622 \mathrm{~cm}^{-1}$ in MRSB-Mo. In view of the existing literature, such lower shifting of $\nu(\mathrm{C}=\mathrm{N})_{\text {imine }}$ peak confirmed the coordination of imine group with molybdenum(vi) center. ${ }^{36 a}$ Apart from this, the peaks due to $\nu(\mathrm{C}=\mathrm{N})_{\text {pyridine, }}$ Py(in-plane ring deformation) and Py(out-of- plane ring deformation) were shifted to higher wave no after molybdenum(vi) coordination. This type of shifting suggest the coordination of pyridine with the metal center. ${ }^{37,38 a}$ Thus the FTIR spectral analysis clearly showed the formation of MR-C, MR-SB and MR-SB-Mo.

The Raman spectral analysis further confirmed the formation of MR-C, MR-SB and MR-SB-Mo that shown by FTIR analysis. The spectral data of the samples are given in Table 3 and the spectrum for MR-SB-Mo is shown in Fig. 5. The strong peaks appeared commonly in each of the spectrum at ca. 1600 and $1000 \mathrm{~cm}^{-1}$ are attributed to the benzene skeletal vibrations arising from the polymeric backbone. ${ }^{32 a, 40}$ The weak peak appeared at $1260 \mathrm{~cm}^{-1}$ due to $\nu(\mathrm{C}-\mathrm{Cl})$ mode of $-\mathrm{CH}_{2} \mathrm{Cl}$ group in MR was absent in MR-C. ${ }^{40 a}$ This observation is in consistent with the results obtained from IR spectral analysis. The very weak peak appeared in the spectrum of MR-C at $1730 \mathrm{~cm}^{-1}$ is attributed to the $\nu(\mathrm{C}=\mathrm{O})$ mode of aldehydic group. Similar to IR spectral analysis, this peak was vanished in the spectrum of MRSB due to the Schiff base formation. The $\nu(\mathrm{C}=\mathrm{N})_{\text {imine }}$ and $\nu(\mathrm{C}=$ $\mathrm{N})_{\text {pyridine }}$ peaks were appeared as medium intensity shoulder in the spectrum of MR-SB. However, after complex formation in MR-SB-Mo, the former peak was shifted to lower wave number and the latter was shifted to higher wave number that confirmed the coordination of the imine and pyridine moieties with the molybdenum(vi) center (through nitrogen atom). Further, the Raman spectrum of MR-SB-Mo displayed two strong peaks at 962 and $910 \mathrm{~cm}^{-1}$ for $\nu(\mathrm{O}=\mathrm{Mo}=\mathrm{O})_{\text {asym }}$ and $\nu(\mathrm{O}=\mathrm{Mo}=\mathrm{O})_{\text {sym }}$, respectively. These two peaks are characteristic of dioxomolybdenum(vi) moiety. ${ }^{41}$ Thus, the Raman spectral analysis confirmed the formation of MR-C, MR-SB and MRSB-Mo.

The diffuse reflectance UV-visible spectra of MR-SB and MRSB-Mo were recorded by taking $\mathrm{BaSO}_{4}$ as reference. The spectrum of MR-SB display two well resolved peaks at ca. 264 and $345 \mathrm{~nm}$. The relatively higher energy peaks at $264 \mathrm{~nm}$ corresponds to the $\pi \rightarrow \pi^{*}$ transition of the pyridyl ring, benzene ring of polymeric support and imine functional group. ${ }^{37,42}$ On the other hand, the lower energy peak at $345 \mathrm{~nm}$ may be assigned to $\mathrm{n} \rightarrow \pi^{*}$ transition of the pyridyl ring and imine functional group..$^{37,42}$ Interestingly, in MR-SB-Mo, the peak for $\mathrm{n}$ $\rightarrow \pi^{*}$ transition was shifted to $c a .331 \mathrm{~nm}$. But the peaks for $\pi$ $\rightarrow \pi^{*}$ transition were remained unaffected after complex formation. This blue shift of $\mathrm{n} \rightarrow \pi^{*}$ transition indicate the coordination of molybdenum(vi) via the pyridyl and imine nitrogen. ${ }^{37,42}$ Beside these, there was no LMCT bands present in the UV-Vis spectrum of MR-SB-Mo. This is because those bands generally appear at higher concentration of metal complexes.

The thermal stability of the compounds was studied with the help of TGA-DTG analysis. The thermograms are shown in Fig. 6 and data are presented in Table 4 . The thermograms showed multiple stage of thermal degradation for each of the compounds. The pristine polymer, MR showed three weight loss steps in the temperature range of 291-366, 366-477, and $477-700{ }^{\circ} \mathrm{C}$ with corresponding weight loss of $14.23,39.53$, and $46.24 \%$, respectively. On the basis of available literatures data, the first step of decomposition is attributed to the loss of chloromethylated group and the subsequent steps are 
Table 3 The IR spectral data for MR, MR-C, MR-SB, and MR-SB-Mo ${ }^{a}$

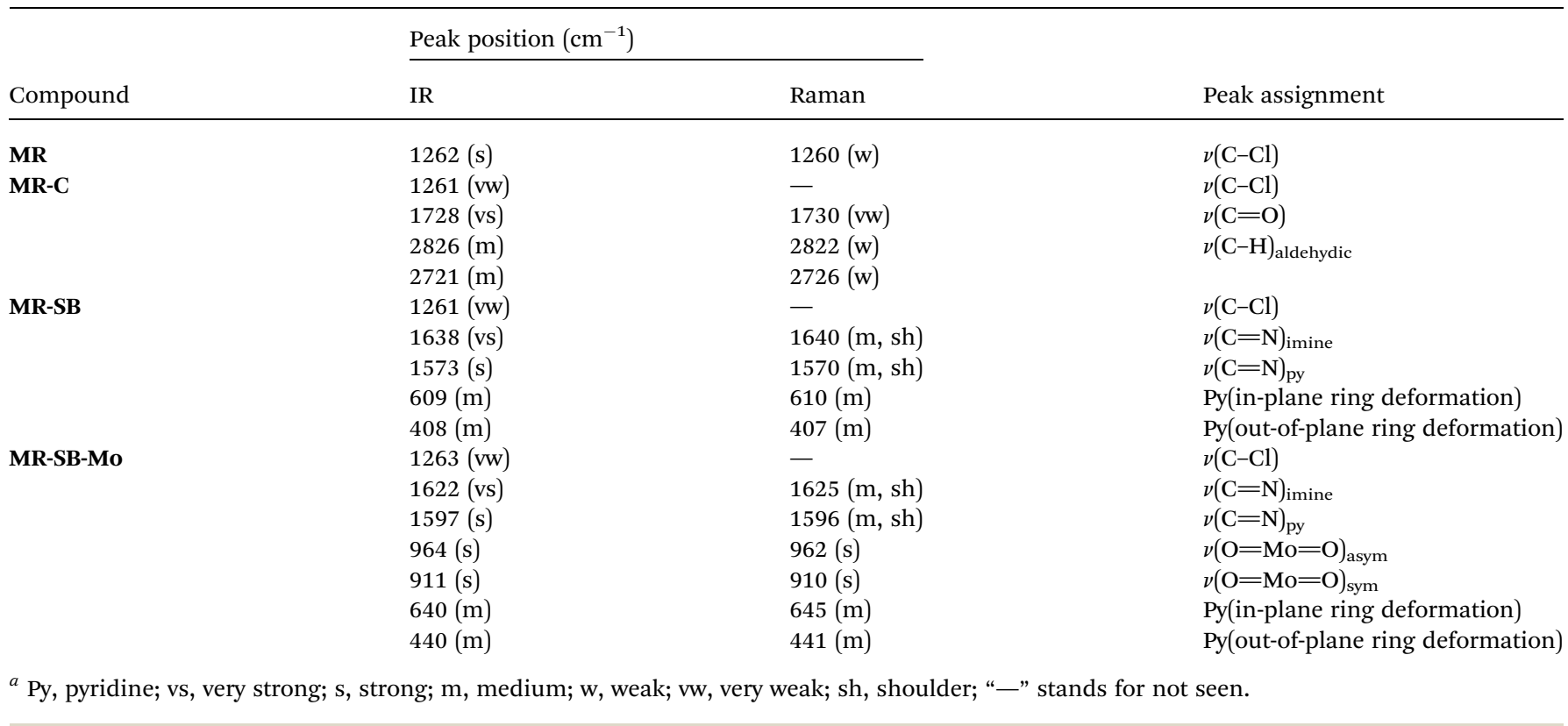

attributed to the decomposition of the cross-linked polystyrene backbone.$^{43}$ The MR was completely decomposed at $c a .700{ }^{\circ} \mathrm{C}$. Similar to MR, MR-C also showed three stage thermal decomposing. The thermogram of MR-SB provided vital information regarding the Schiff base loading on the support. The decomposition at $c a .177-230^{\circ} \mathrm{C}$ with weight loss of $20.77 \%$ matched exactly with the data obtained from elemental analysis for Schiff base loading (20.53\% Schiff base, based on $\mathrm{N}$ content). Further evidence about the loss of Schiff base ligand at this stage was confirmed by recording IR spectrum of the sample at this temperature which did not show the presence of characteristic peak for $\nu(\mathrm{C}=\mathrm{N})_{\text {imine. }}$. The subsequent decomposition steps are attributed to the decomposition of the polystyrene backbone. The thermogram of MR-SB-Mo showed four steps of thermal degradation at the temperature range of 195-234, 299-350, 350486 , and $486-700{ }^{\circ} \mathrm{C}$ with the corresponding weight loss of $18.86,2.34,29.90$, and $39.27 \%$, respectively. Interestingly, the compound never decomposed completely upto $700{ }^{\circ} \mathrm{C}$ which

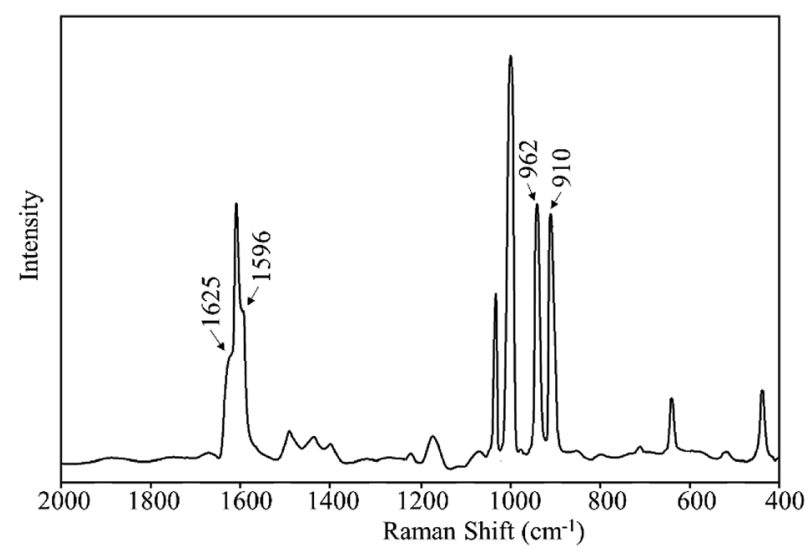

Fig. 5 Raman spectrum for MR-SB-Mo. was due to the residual oxo-molybdenum species formed after complete decomposition of polymeric materials. ${ }^{32 a, 44}$ The thermal stability of upto $195{ }^{\circ} \mathrm{C}$ for MR-SB-Mo also provide additional evidence about the stability of the catalyst under different reaction temperatures.

On the basis of the above analysis, a structure for MR-SB-Mo is proposed as shown in Scheme 1 where a dioxomolybdenum(vi) species is anchored to the support via coordination with the nitrogen atom of imine and pyridine group.

\subsection{Catalytic activity}

3.3.1 Oxidation of alcohols to aldehydes or ketones catalyzed by MR-SB-Mo. The catalytic oxidation of alcohols to ketones (in case of secondary alcohols) or aldehydes (in case of benzylic and primary alcohols) by MR-SB-Mo using aqueous $\mathrm{H}_{2} \mathrm{O}_{2}$ as oxidant has been studied under solventless condition.

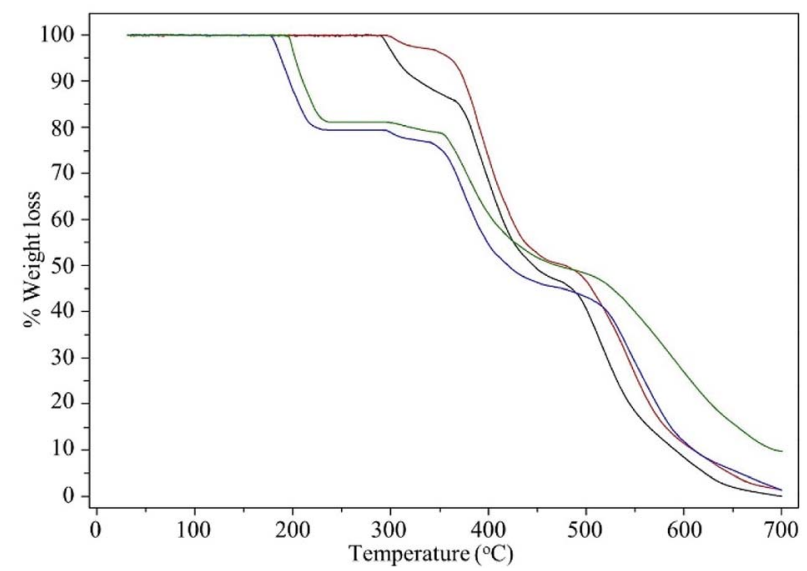

Fig. 6 The TGA thermograms of MR (black), MR-C (red), MR-SB (blue), and MR-SB-Mo (green). 
Table 4 The TGA-DTG analysis data for MR, MR-C, MR-SB, and MRSB-Mo

\begin{tabular}{lcc}
\hline Compound & Temperature, ${ }^{\circ} \mathrm{C}$ & Weight loss $(\%)$ \\
\hline MR & $291-366$ & 14.23 \\
& $366-477$ & 39.53 \\
& $477-700$ & 46.24 \\
MR-C & $296-344$ & 3.27 \\
& $344-480$ & 46.74 \\
& $480-700$ & 48.92 \\
MR-SB & $177-230$ & 20.77 \\
& $294-340$ & 2.46 \\
& $340-480$ & 32.08 \\
MR-SB-Mo & $480-700$ & 43.47 \\
& $195-234$ & 18.86 \\
& $299-350$ & 2.34 \\
& $350-486$ & 29.90 \\
& $486-700$ & 39.27
\end{tabular}

The alcohols may be oxidized to aldehydes, ketones or carboxylic acids. The product selectivity depends upon the employed reaction conditions as discussed below.

In order to gain a standard reaction condition for product selectivity and better yield for oxidation of alcohols to ketones or aldehydes several reaction parameters such as solvents, amount of catalyst and oxidant, reaction temperature, etc. were screened using benzyl alcohol as model substrate.

In the initial investigation, the oxidation of benzyl alcohol was carried out with varying amount of $30 \%$ aqueous $\mathrm{H}_{2} \mathrm{O}_{2}$ as oxidant. We have conducted the reactions by keeping the molar ratios of benzyl alcohol : $\mathrm{H}_{2} \mathrm{O}_{2}$ at $1: 0.5,1: 1.1,1: 1.5$ and $1: 2$ and Mo: benzyl alcohol at $1: 1000$. The results are summarized in Table 5. The reaction at molar ratio of $1: 0.5$ was not completed even after $5 \mathrm{~h}$ [Table 5 , entry 1 ]. So, we have increased the amount of $\mathrm{H}_{2} \mathrm{O}_{2}$ to $1: 1.1$, i.e., slightly excess than the substrate. At this molar ratio, the reaction comfortably completed in $90 \mathrm{~min}$ with benzaldehyde as the sole product [Table 5, entry 2]. With a view to decrease the reaction time, we have further conducted the reactions at $1: 1.5$ and $1: 2$, but product selectivity was lost and formed $6 \%$ and $9 \%$ of benzoic acid, respectively [Table 5, entries 3 and 4]. Thus, the molar ratio of substrate : $\mathrm{H}_{2} \mathrm{O}_{2}$ at $1: 1.1$ is found to be the optimum condition for selectively oxidize benzyl alcohol to benzaldehyde.

Keeping the molar ratio of substrate: $\mathrm{H}_{2} \mathrm{O}_{2}$ at $1: 1.1$, we have screened the oxidation of benzyl alcohol by using different solvents such as water, acetonitrile, chloroform, dichloromethane, toluene, etc. as well as under solventless condition. The highest activity in terms of TOF was found in solventless condition [Table 5, entry 2]. The reaction conducted in water decreased the TOF [Table 5, entry 5]. This may be due to dilution of the reaction mixture by the added water. In acetonitrile, the reactivity is not improved [Table 5, entry 6]. Further, reactions in chloroform and dichloromethane are very slow with poor TOF [Table 5, entries 7 and 8]. This may be due to the immiscibility of the oxidant with the solvents. Moreover, we do not intend to use halogenated solvents. Similar type of reactivity was also found while doing reaction in toluene [Table 5, entry 9]. The use of methanol and ethanol were avoided as these solvents may compete for oxidation. Indeed, the reactions were very slow and not completed (data not shown). Thus, solventless condition was found to be optimum for selectively oxidize benzyl alcohol to benzaldehyde.

The catalyst amount has a great impact on TOF. We have conducted reactions by keeping molar ratio of Mo: benzyl alcohol at $1: 100,1: 500$ and $1: 1000$. Each of the reactions were conducted by keeping benzyl alcohol: $\mathrm{H}_{2} \mathrm{O}_{2}$ at $1: 1.1$ and under solventless condition at $65{ }^{\circ} \mathrm{C}$. There was decrease in reaction time with increased amount of catalyst but the TOF was significantly decreased [Table 5, entries 2, 10 and 11].

Reactions were conducted with $6 \%, 30 \%$ and $50 \%$ of aqueous $\mathrm{H}_{2} \mathrm{O}_{2}$ solutions [Table 5, entries 2, 12 and 13] at molar ratio of benzyl alcohol: $\mathrm{H}_{2} \mathrm{O}_{2}$ and $\mathrm{Mo}$ : benzyl alcohol at 1 : 1.1 and $1: 1000$, respectively under solventless condition at $65{ }^{\circ} \mathrm{C}$. The slowest reaction and lowest TOF was found with $6 \% \mathrm{H}_{2} \mathrm{O}_{2}$ whereas fastest was found with $50 \% \mathrm{H}_{2} \mathrm{O}_{2}$ [Table 5, entry 13]. However, trace amount of carboxylic acid was formed with $50 \%$ $\mathrm{H}_{2} \mathrm{O}_{2}$, i.e., loss of product selectivity. The slowest reaction with $6 \% \mathrm{H}_{2} \mathrm{O}_{2}$ may be due to the dilution of the oxidant in the reaction mixture as was found in case of reactions in water as solvent [Table 5, entry 5]. Therefore, we have chosen $30 \% \mathrm{H}_{2} \mathrm{O}_{2}$ as optimum for this reaction.

We have also screened the reaction with different types of oxidant such as $30 \% \mathrm{H}_{2} \mathrm{O}_{2}$ (aqueous), $t$-butyl hydroperoxide (70\% aqueous solution, TBHP), air and $\mathrm{O}_{2}$ balloon. The highest TOF was found with $30 \% \mathrm{H}_{2} \mathrm{O}_{2}$ [Table 5, entry 2] and no reaction with air or $\mathrm{O}_{2}$ balloon under identical reaction conditions [Table 5, entries 15 and 16]. There were 3 to 4 -fold increase in reaction time with TBHP [Table 5, entry 14] as an oxidant. Moreover, it was reported that TBHP generates butanol as byproduct. ${ }^{45}$ Interestingly, the use of $\mathrm{H}_{2} \mathrm{O}_{2}$ is advantageous as it is cheap, environmentally clean, easy to handle and water is the only byproduct. ${ }^{\boldsymbol{c} \boldsymbol{a}-\boldsymbol{c}, \boldsymbol{e}, \boldsymbol{g}}$

The reaction temperature has a remarkable impact on rate of reaction. So, we have conducted reactions at different temperatures viz. room temperature, 50, 65, and $90^{\circ} \mathrm{C}$ [Table 5, entries 2, 17-19]. The reactions were conducted under solventless condition by keeping molar ratio of benzyl alcohol : $\mathrm{H}_{2} \mathrm{O}_{2}$ $(30 \%):$ Mo at $1000: 1100: 1$. It was found that with increasing reaction temperature, the TOF increases and reached a highest value at $65{ }^{\circ} \mathrm{C}$. Thereafter, the TOF decreases which indicates that $65{ }^{\circ} \mathrm{C}$ is the optimum reaction temperature.

Thus the optimum reaction condition for the selective oxidation of benzyl alcohol to benzaldehyde was found to be substrate : $\mathrm{H}_{2} \mathrm{O}_{2}(30 \%)$ : Mo at $1000: 1100: 1$ under solventless condition at $65{ }^{\circ} \mathrm{C}$ as shown in Scheme 2 .

Having gained the optimal conditions, we explored the substrate scope of the newly developed catalyst, MR-SB-Mo under the optimum condition, for the selective oxidation of a wide range of alcohols such as primary, secondary and benzyl alcohols to their corresponding aldehydes or ketones. The results are summarized in Table 6 . It is seen from the table that each of the substrate oxidized in high yields with reasonably good TOF. Besides this, under same reaction conditions, benzylic [Table 6, entries 1-9] and secondary alcohols [Table 6, entries 10-15] were found to be oxidize relatively at faster rate 
Table 5 Optimization of reaction conditions catalyzed by MR-SB-Mo ${ }^{a}$

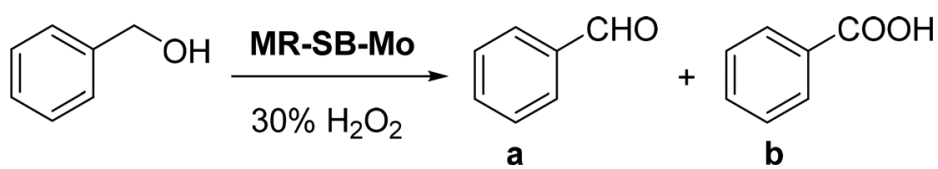

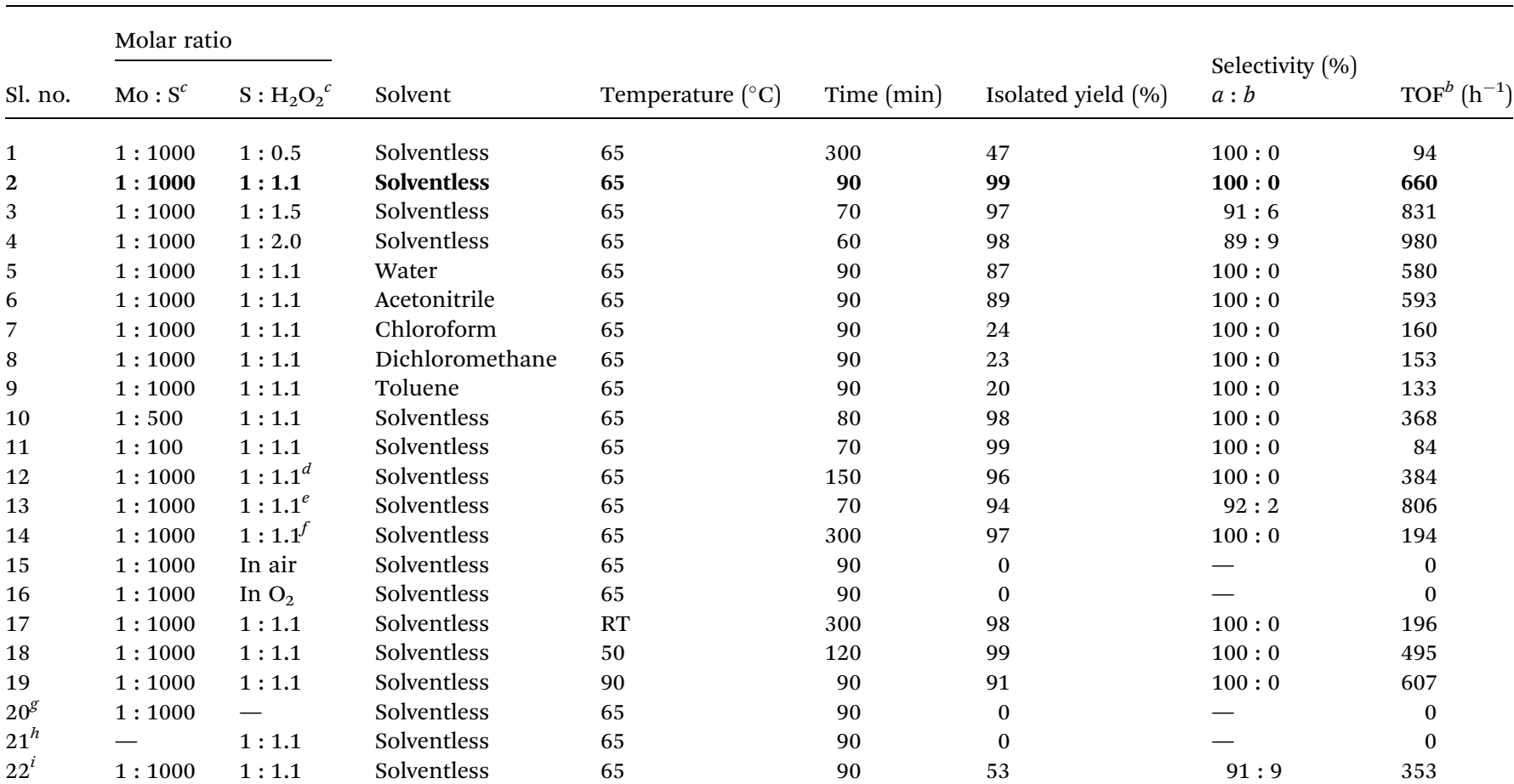

${ }^{a}$ All reactions were carried out with benzyl alcohol as substrate (2.5 mmol), MR-SB-Mo (5.6 mg for $0.0025 \mathrm{mmol}$ of Mo) and $5 \mathrm{~mL}$ solvent (unless otherwise indicated $) .{ }^{b} \mathrm{TOF}=(\mathrm{mmol}$ of product $) /[(\mathrm{mmol}$ of catalyst $) \times($ time $)] .{ }^{c}$ ' $\mathrm{S}$ ' stands for substrate. ${ }^{d}$ Reaction with $6 \%$ aqueous $\mathrm{H}_{2} \mathrm{O}_{2}$ as oxidant. ${ }^{e}$ Reaction with $50 \%$ aqueous $\mathrm{H}_{2} \mathrm{O}_{2}$ as oxidant. ${ }^{f}$ Reaction with $70 \%$ aqueous TBHP as oxidant. ${ }^{g}$ Reaction conducted with MR-SB-Mo but no added oxidant. ${ }^{h}$ Reaction conducted without MR-SB-Mo or blank reaction. ${ }^{i}$ Reaction conducted under optimum condition with SB-Mo $(1.5 \mathrm{mg}, 0.0025 \mathrm{mmol})$ as catalyst.

than the primary alcohols [Table 6 , entries $16-20]$. The beauty of the protocol is that no overoxidation to carboxylic acid took place with all the studied substrates. In case of substituted benzyl alcohols, different types of substituents such as $-\mathrm{F},-\mathrm{Cl}$, $-\mathrm{Br},-\mathrm{OMe},-\mathrm{OH}$ and $-\mathrm{NO}_{2}$ well-tolerate during the oxidation process [Table 6, entries 2-7], some of which could be utilized for further derivation. One of the notable aspect of the developed catalytic system is its ability to oxidize benzyl alcohol to benzaldehyde at relatively higher scale $(10 \mathrm{~g}$ scale) without losing the catalytic efficiency and product selectivity [Table 6, entry $1^{d}$ ] which provides its potential application towards commercial processes. It is pertinent here to mentioned that in a separate blank reaction using benzyl alcohol as substrate, i.e.,

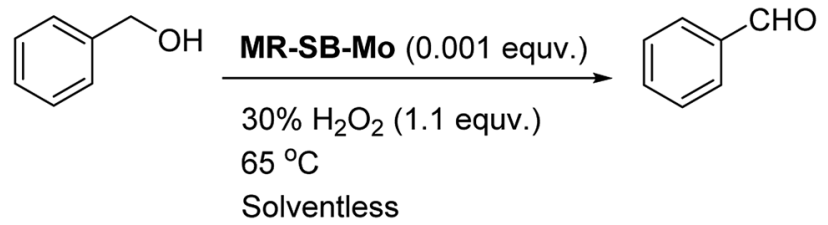

Scheme 2 Optimum reaction condition for oxidation of alcohol catalyzed by MR-SB-Mo using $30 \% \mathrm{H}_{2} \mathrm{O}_{2}$ as oxidant. under identical optimum conditions without the added catalyst, the reaction did not progress within the stipulated time which indicate the active role of the catalyst in the oxidation processes (Table 5 , entry 21). Similarly, the reaction was not successful without the added $\mathrm{H}_{2} \mathrm{O}_{2}$ (Table 5, entry 20).

In order to check the advantage of synthesizing the heterogeneous catalyst, MR-SB-Mo, over homogeneous catalyst, a neat dioxomolybdenum complex, SB-Mo was synthesized (detailed synthetic procedure is in ESI $†$ ). The ligand for the neat complex was designed in such a way that it provides almost identical coordination environment that present in MR-SB-Mo. Moreover, the catalytic oxidation reaction was conducted under identical optimum condition using benzyl alcohol as substrate. From the reaction it was seen that the SB-Mo could reached upto TOF $=353 \mathrm{~h}^{-1}$ within the stipulated time period (Table 5, entry 22) and produced benzaldehyde along with benzoic acid (9\%). Thus, under identical optimum condition the heterogeneous catalyst, MR-SB-Mo showed superior catalytic activity in terms of product yield as well as product selectivity over the homogeneous catalyst, SB-Mo.

In order to compare the catalytic activity of MR-SB-Mo over the reported catalyst, a separate comparison table containing 
Table 6 Oxidation of alcohols to aldehydes or ketones catalyzed by MR-SB-Mo using $30 \%$ aqueous $\mathrm{H}_{2} \mathrm{O}_{2}$ as oxidant ${ }^{a}$

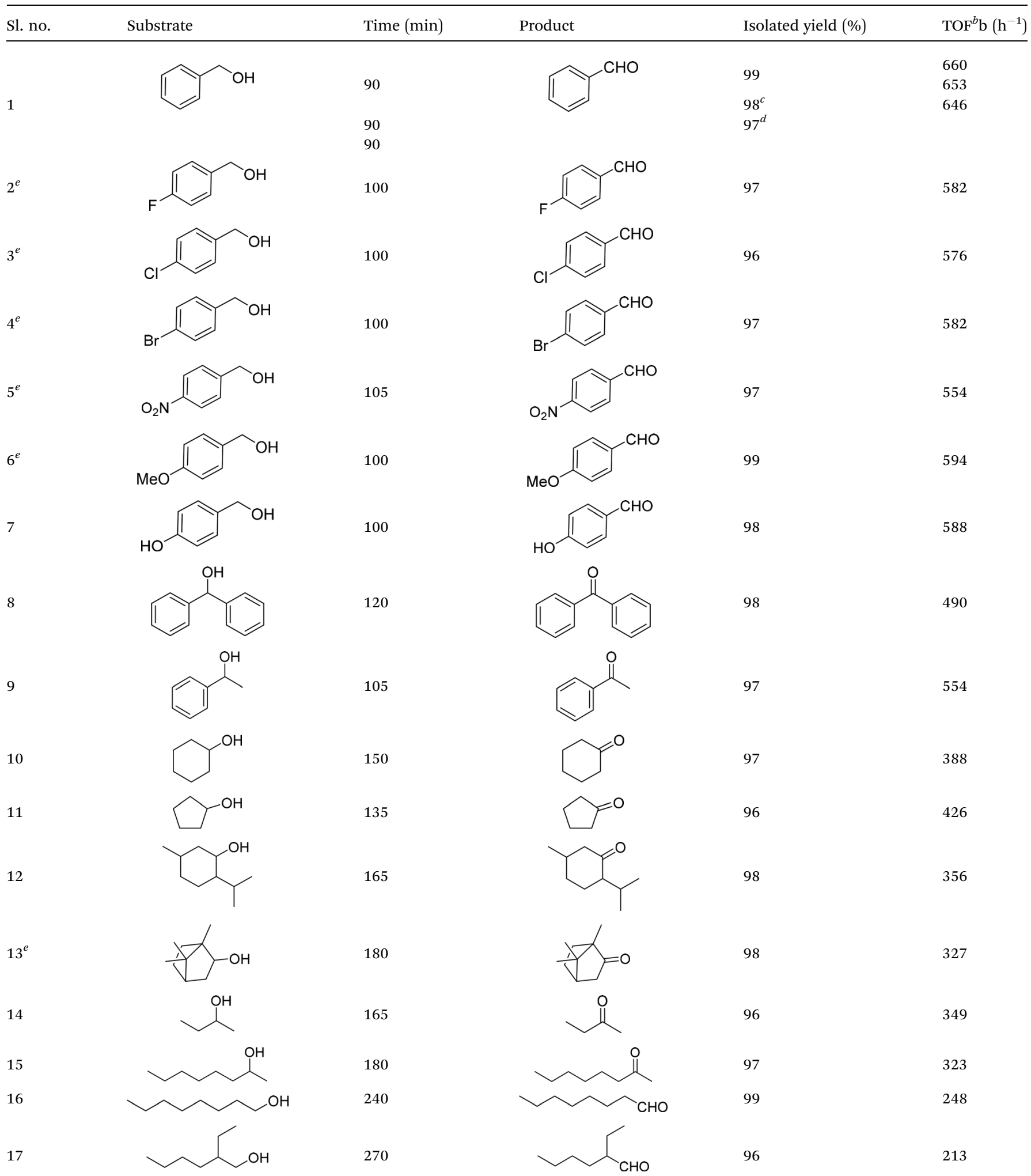


Table 6 (Contd.)

\begin{tabular}{lllllc}
\hline Sl. no. & Substrate & Time $(\mathrm{min})$ & Product & Isolated yield $(\%)$ & TOF $^{b} \mathrm{~b}\left(\mathrm{~h}^{-1}\right)$ \\
\hline 18 & $\mathrm{CH}_{3}\left(\mathrm{CH}_{2}\right)_{3} \mathrm{CH}_{2} \mathrm{OH}$ & 240 & $\mathrm{CH}_{3}\left(\mathrm{CH}_{2}\right)_{3} \mathrm{CHO}$ & 97 & 243 \\
19 & $\mathrm{CH}_{3}\left(\mathrm{CH}_{2}\right)_{8} \mathrm{CH}_{2} \mathrm{OH}$ & 270 & $\mathrm{CH}_{3}\left(\mathrm{CH}_{2}\right)_{8} \mathrm{CHO}$ & 98 & 218 \\
20 & $\mathrm{CH}_{3}\left(\mathrm{CH}_{2}\right)_{2} \mathrm{CH}_{2} \mathrm{OH}$ & 240 & $\mathrm{CH}_{3}\left(\mathrm{CH}_{2}\right)_{8} \mathrm{CHO}$ & 96 & 240
\end{tabular}

${ }^{a}$ Reaction conditions: unless otherwise stated, all reactions were performed solventless at $65{ }^{\circ} \mathrm{C}$ using $2.5 \mathrm{mmol}$ of substrate, $5.6 \mathrm{mg}$ of MR-SB-Mo (contain $0.0025 \mathrm{mmol}$ of Mo) and $2.75 \mathrm{mmol}$ of $30 \%$ aqueous $\mathrm{H}_{2} \mathrm{O}_{2} \cdot{ }^{b}$ TOF $=(\mathrm{mmol}$ of product $) /\left[(\mathrm{mmol}\right.$ of catalyst) $\times($ time $)]{ }^{c}$ Yield at $5^{\text {th }}$ reaction cycle. ${ }^{d}$ Yield at $10 \mathrm{~g}$ scale reaction. ${ }^{e}$ Reaction conducted with $2 \mathrm{~mL}$ acetonitrile.

catalytic activity of reported molybdenum-based catalyst towards oxidation of benzyl alcohol is given in ESI (Table S1 $\dagger$ ). From the table it is seen that MR-SB-Mo exhibit superior activity over the reported catalysts.

3.3.2 Catalyst recycling. Recycling of the catalyst, MR-SBMo was examined under the optimum condition using benzyl alcohol as substrate. In the typical procedure, after completion of the reaction, the spent solid catalyst was separated from the reaction mixture by filtration, washed with acetonitrile, dried in vacuo, and used for the subsequent reaction cycles without any further treatment. Fig. 7 shows the result of the recycling experiments for five catalytic cycles. It was found that the catalyst efficiently and selectively oxidized benzyl alcohol to benzaldehyde without loss of its activity atleast upto fifth reaction cycles [Table 6 , entry $1^{c}$ ]. No change in reaction yield and time were found even after the fifth reaction cycle. The FT-IR and XPS spectra of the spent solid catalyst recorded after fifth reaction cycle [Fig. 3(b) and 4(e)] were found to be identical with the fresh MR-SB-Mo. Moreover, the AAS analysis showed no significant loss of molybdenum content in the spent catalyst [Table 1]. These confirmed the stability and robustness of the catalyst in the oxidation process in presence of $\mathrm{H}_{2} \mathrm{O}_{2}$.

3.3.3 Test for heterogeneity of the reaction. In order to test the leaching of the molybdenum complex from the polymer support, a separate experiment was carried out at optimum condition using benzyl alcohol as substrate. In the typical procedure, the reaction was run without the substrate, i.e.,

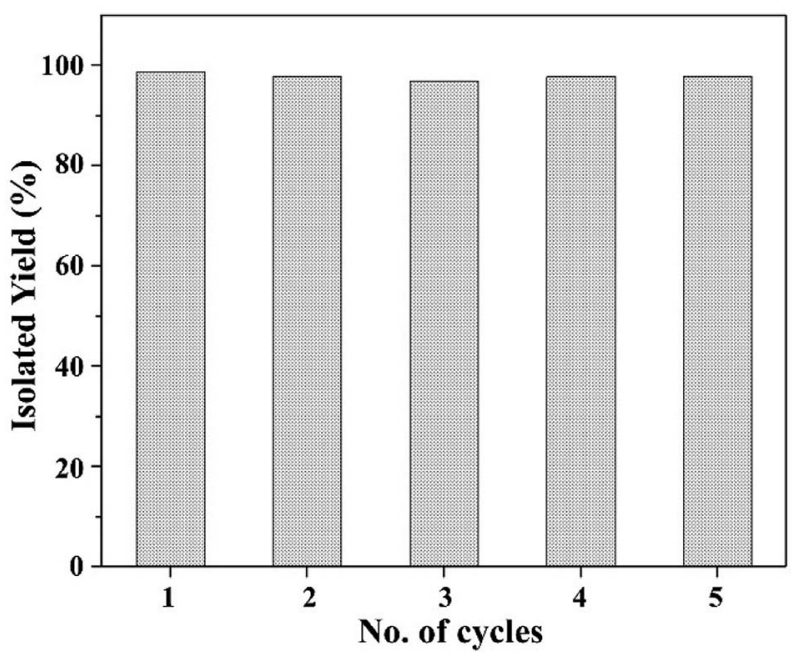

Fig. 7 Catalyst recycling. benzyl alcohol for $90 \mathrm{~min}$ at $65{ }^{\circ} \mathrm{C}$. Subsequently, the reaction mixture was filtered and separated the solid catalyst. To the filtrate, a fresh lot of benzyl alcohol and $\mathrm{H}_{2} \mathrm{O}_{2}$ were added and continued the reaction under identical condition for $90 \mathrm{~min}$. No oxidation reaction was observed which is in agreement with the absence of metal leaching and pure heterogeneity of the catalytic process. Moreover, the AAS and ICP-OES elemental analysis showed no molybdenum in the filtrate.

3.3.4 Mechanism of alcohol oxidation. On the basis of our observations and the available literature data ${ }^{\mathbf{1 4 f , 4 6}}$ for the oxidation reactions mediated by oxometal complexes, a mechanism is proposed in Scheme 3 for the catalytic activity of MR-SBMo. The catalyst, MR-SB-Mo which is a dioxomolybdenum(vi) complex, I is inactive as such in the oxidation process reacts with a hydrogen peroxide molecule via path [a] to form the peroxomolybdenum(vi) complex, II. The complex II is active in oxidation and oxidized the alcohol via path [b]. After oxidation, the active complex II became inactive and form complex I which is again reactivated by a new hydrogen peroxide molecule. This way the catalytic cycle is repeated. The formation of such active peroxomolybdenum(vi) complex, II from the inactive dioxomolybdenum(vi) complex, I by the reaction of hydrogen peroxide in the catalytic oxo-transfer process is well documented in literature. ${ }^{\mathbf{1 4 f , 4 6}}$ Interestingly, in a separate experiment, we could isolate a peroxomolybdenum(vi) complex from MR-SB-Mo. In the typical experiment, MR-SB-Mo was treated with excess hydrogen peroxide in an ice-bath and the products were isolated by filtration, washed with acetonitrile and dried in vacuo. The original slightly brownish polymeric beads were changed into reddish color. The FTIR spectra for the reddish color beads is presented in Fig. S2(a) (ESI $\dagger$ ) which shows the presence of characteristic peaks for $\nu(\mathrm{O}-\mathrm{O}), \nu_{\text {sym }}\left(\mathrm{Mo}-\mathrm{O}_{2}\right)$ and $\nu_{\text {sym }}\left(\mathrm{Mo}-\mathrm{O}_{2}\right)$ in the vicinity of $c a .856(\mathrm{~s}), 632(\mathrm{~m})$, and $514(\mathrm{~m}) \mathrm{cm}^{-1}$, respectively. These peaks are attributed to a peroxometal moiety. ${ }^{32 a, 44}$

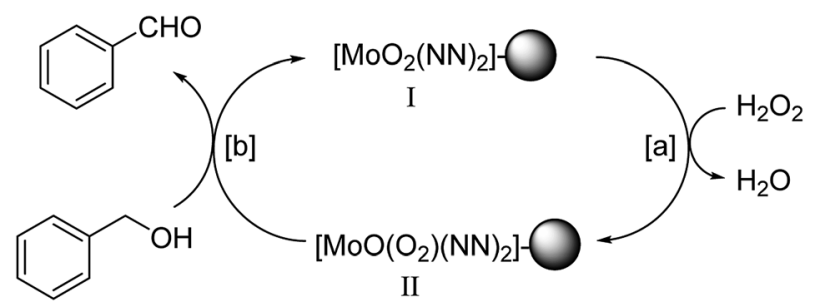

Scheme 3 Proposed reaction mechanism for oxidation of alcohols using benzyl alcohol as representative. "NN" stands for the nitrogen coordination site for imine and pyridine group and " $Q$ " represents polymeric support. 
Unfortunately, the isolated peroxo complex was not stable for prolonged period and gradually vanished the reddish color within two days. The FTIR spectra of the sample recorded at this stage showed the absence of peaks responsible for peroxometal moiety. But the IR spectrum was identical with the spectrum for MR-SB-Mo (Fig. S2(b), ESI $\dagger$ ). This observation suggested that the MR-SB-Mo is converted into an active peroxometal moiety (may be II) by the reaction with the additional hydrogen peroxide which is revert back to its original form (MR-SB-Mo) after the oxidation reaction.

The change of substituents in the ligand environment of the metal complexes lead to a dramatic change in their catalytic activity. In this regard, the Hammett relation ${ }^{47}$ can be used to predict the catalytic activity of MR-SB-Mo. The substituent constant, $\sigma$ of Hammett equation, for the substituents with $(+)$ ve and (-)ve values indicate the electron withdrawing and electron releasing group, respectively. Thus, choosing substituents from the series could help to design a better catalyst for their activity. From the available literature report, ${ }^{\mathbf{1 4 f , 4 7 , 4 8}}$ it is found that oxidation of alcohol by the peroxometal complexes take place by electrophilic attack of the peroxo moiety on the oxygen atom of the alcohol group $(-\mathrm{OH})$. Thus, adding substituents with (+)ve $\sigma$-value in the ligand environment of MR-SB-Mo will increase the electrophilicity of the peroxo moiety which in return increase the catalytic activity of the catalyst. The catalyst, MR-SB-Mo can be substituted in its both the aromatic rings viz. phenyl or pyridyl ring. So, the synthesis of MR-SB-Mo with electron withdrawing substituents anticipated a higher reaction rate.

\section{Conclusions}

In summary, we have developed a heterogeneous molybdenum(vi) based catalyst using Schiff base functionalized Merrifield resin as support. The compound, MR-SB-Mo, served as an efficient catalyst for the selective oxidation of alcohols to aldehydes or ketones using $30 \%$ aqueous $\mathrm{H}_{2} \mathrm{O}_{2}$ as an oxidant, which is considered as a Green oxidant, under solvent-less condition. The catalyst showed recyclability atleast upto $5^{\text {th }}$ reaction cycles without loss of activity and product selectivity. The developed protocol for the oxidation of alcohols is simple and the products were isolated in highly pure form. On the basis of available literature reports (Table S1, ESI $\dagger$ ), the catalyst is found to offer reasonably good catalytic activity and higher TOF. Thus, the protocol complies with the principles of "Green Chemistry" which is very important in concern with the current environmental prospects.

\section{Conflicts of interest}

There are no conflicts of interest to declare.

\section{Acknowledgements}

J. J. B. acknowledges University Grants Commission, New Delhi, India for providing financial support under Minor Research Project (No. F. 5-30/2013-14/MRP/NERO/427). We are also thankful to Sophisticated Analytical Instrumentation Centre (SAIC), Tezpur University, Sonitpur, Assam, India and Centre of Excellence, NFDD Centre, Saurashtra University, Rajkot, Gujarat, India for recording the FTIR and UV-Vis spectra, TGADTG thermogram and BET analysis.

\section{References}

1 (a) M. Hudlicky, Oxidation in Organic Chemistry, ACS Monograph Series no. 186, American Chemical Society, Washington DC, 1990; (b) R. A. Sheldon and J. K. Kochi, Metal-Catalyzed Oxidations of Organic Compounds, Academic Press, London, 1981; (c) S. Caron, R. W. Dugger, S. G. Ruggeri, J. A. Ragan and D. H. B. Ripin, Chem. Rev., 2006, 106, 2943-2989; (d) M. Beller, Adv. Synth. Catal., 2004, 346, 107-108; (e) J. Cai, J.-Y. Lu, Q.-Y. Chen, L.-L. Qu, Y.-Q. Lub and G.-F. Gao, New J. Chem., 2017, 41, 38823886; (f) Z. Hao, N. Li, X. Yan, Y. Li, S. Zong, H. Liu, Z. Han and J. Lin, New J. Chem., 2018, 42, 6968-6975; (g) S. Farhadi, M. Hakimib and M. Maleki, RSC Adv., 2018, 8, 6768-6780; (h) W. C. de Abreu, M. A. S. Garcia, S. Nicolodi, C. V. R. de Moura and E. M. de Moura, RSC Adv., 2018, 8, 3903-3909.

2 K. Tornheim and N. B. Ruderman, Intermediary Metabolism of Carbohydrate, Protein, and Fat, in Metabolic Basis of Obesity, ed. R. S. Ahima, Springer, New York, 2011, pp 25-51.

3 J. March, Advanced Organic Chemistry: Reactions, Mechanisms, and Structure, John Wiley \& Sons: New York, 4 edn, 1992.

4 (a) N. Bhati, K. Sarma and A. Goswami, Synth. Commun., 2008, 38, 1416-1424; (b) S. Biella and M. Rossi, Chem. Commun., 2003, 378-379; (c) H. Ünver and I. Kani, Polyhedron, 2017, 134, 257-262.

5 M. N. Kopylovich, A. P. C. Ribeiro, E. C. B. A. Alegria, N. M. R. Martins, L. M. D. R. S. Martins and A. J. L. Pombeiro, Catalytic Oxidation of Alcohols: Recent Advances in Advances in Organometallic Chemistry, ed. P. J. Pérez, 2015, 63, pp 91-174.

6 (a) R. Noyori, M. Aokib and K. Sato, Chem. Commun., 2003, 1977-1986; (b) K. Kaczorowska, Z. Kolarska, K. Mitkab and P. Kowalski, Tetrahedron, 2005, 61, 8315-8327; (c) K. Sato, M. Aoki and R. Noyori, Science, 1998, 281, 1646-1647; (d) B. S. Lane and K. Burgess, Chem. Rev., 2003, 103, 24572474; (e) C. W. Jones, Applications of Hydrogen Peroxide and Derivatives, Royal Society of Chemistry, Cambridge, 1999; (f) K. Sato, M. Aoki, M. Ogawa, T. Hashimoto and R. Noyori, J. Org. Chem., 1996, 61, 8310-8311; (g) B. Karimi, M. Ghoreishi-Nezhad and J. H. Clark, Org. Lett., 2005, 7, 625-628.

7 (a) L. I. Simándi, Catalytic Activation of Dioxygen by Metal Complexes, Kluwer Academic, Dordrecht, The Netherlands, 1992; (b) The Activation of Dioxygen and Homogeneous Catalytic Oxidation, ed. D. H. R. Barton, A. E. Bartell and D. T. Sawyer, Plenum, New York, 1993; (c) M. Haruta, Catal. Today, 1997, 36, 153-166; (d) R. Meiers, U. Dingerdissen and W. F. Holderich, J. Catal., 1998, 176, 376-386. 
8 N. D. Gillitt, J. Domingos and C. A. Bunton, J. Phys. Org. Chem., 2003, 16, 603-607.

9 (a) A. Butler, M. J. Clague and G. E. Meister, Chem. Rev., 1994, 94, 625-638; (b) U. R. Pillai and E. Sahle-Demessie, Appl. Catal., A, 2004, 276, 139-144; (c) H. Veisi, P. Safarimehr and S. Hemmati, J. Taiwan Inst. Chem. Eng., 2018, 88, 8-17; (d) S. D. Kurbah, M. Asthana, I. Syiemlieh and R. A. Lal, Appl. Organomet. Chem., 2018, 32, e4299; (e) A. L. Cánepa, V. R. Elías, V. M. Vaschetti, E. V. Sabre, G. A. Eimer and S. G. Casuscelli, Appl. Catal., A, 2017, 545, 72-78; (f) R. A. Sheldon, Catal. Today, 2015, 247, 4-13; $(g)$ B. Eftekhari-Sis, M. Akbari, A. Akbari and M. Amini, Catal. Lett., 2017, 147, 2106-2115.

10 (a) G. B. Shul'pin, Y. N. Kozlov, L. S. Shul'pina and P. V. Petrovskiy, Appl. Organomet. Chem., 2010, 24, 464472; (b) L. S. Shul'pina, D. Veghini, A. R. Kudinov and G. B. Shul'pin, React. Kinet. Catal. Lett., 2006, 88, 157-163.

11 (a) B. A. Steinhoff, S. R. Fix and S. S. Stahl, J. Am. Chem. Soc., 2002, 124, 766-767; (b) G.-J. ten Brink, I. W. C. E. Arends and R. A. Sheldon, Science, 2000, 287, 1636-1639; (c) P. Saxena and R. Murugavel, ChemistrySelect, 2017, 2, 3812-3822.

12 (a) V. Kogan, M. M. Quintal and R. Neumann, Org. Lett., 2005, 7, 5039-5042; (b) G. Barak, J. Dakka and Y. Sasson, J. Org. Chem., 1988, 53, 3553-3555.

13 (a) R. V. Ottenbacher, E. P. Talsi and K. P. Bryliakov, Chem. Rec., 2018, 18, 78-90; (b) C. Miao, X.-X. Li, Y.-M. Lee, C. Xia, Y. Wang, W. Nam and W. Sun, Chem. Sci., 2017, 8, 7476-7482; (c) G. B. Shulpin, G. Süss-Fink and L. S. Shulpina, J. Mol. Catal. A: Chem., 2001, 170, 17-34.

14 (a) M. H. Dickman and M. T. Pope, Chem. Rev., 1994, 94, 569584; (b) K. Sato, M. Aoki, J. Takagi and R. Noyori, J. Am. Chem. Soc., 1997, 119, 12386-12387; (c) B. S. Chhikara, R. Chandra and V. Tandon, J. Catal., 2005, 230, 436-439; (d) K. Sato, J. Takagi, M. Aoki and R. Noyori, Tetrahedron Lett., 1998, 39, 7549-7552; (e) N. Gharah, S. Chakraborty, A. K. Mukherjee and R. Bhattacharyya, Inorg. Chim. Acta, 2009, 362, 1089-1100; (f) S. E. Jacobson, D. A. Muccigrosso and F. Mares, J. Org. Chem., 1979, 44, 921-924.

15 (a) Y. Ishii, K. Yamawaki, T. Yoshida, T. Ura and M. Ogawa, J. Org. Chem., 1987, 52, 1868-1870; (b) S. D. Kurbah, A. Kumar, I. Syiemlieh, M. Asthana and R. A. Lal, Inorg. Chem. Commun., 2017, 86, 39-43.

16 C. Crestini, M. C. Caponi, D. S. Argyropoulos and R. Saladino, Bioorg. Med. Chem., 2006, 14, 5292-5302.

17 (a) R. Behling, G. Chatel and S. Valange, Ultrason. Sonochem., 2017, 36, 27-35; (b) P. B. Bhat, R. Rajarao, V. Sahajwalla and B. R. Bhat, J. Mol. Catal. A: Chem., 2015, 409, 42-49.

18 H. Ünver and I. Kani, J. Chem. Sci., 2018, 130, 33.

19 (a) É. Balogh-Hergovich and G. Speier, J. Mol. Catal. A: Chem., 2005, 230, 79-83; (b) B. Stanje, P. Traar, J. A. Schachner, F. Belaja and N. C. Mösch-Zanetti, Dalton Trans., 2018, 47, 6412-6420.

20 (a) P. T. Anastas and J. C. Warner, Green Chemistry: Theory and Practice, Oxford University Press, New York, 1998; (b) P. Anastas and N. Eghbali, Chem. Soc. Rev., 2010, 39, 301312.
21 (a) S. Liang, L. Wen, S. Lin, J. Bi, P. Feng, X. Fu and L. Wu, Angew. Chem., Int. Ed., 2014, 53, 2951-2955; (b) Q. Lin, L. Li, S. Liang, M. Liu, J. Bi and L. Wu, Appl. Catal., B, 2015, 163, 135-142; (c) K. Jing, J. Xiong, N. Qin, Y. Song, L. Li, Y. Yu, S. Liang and L. Wu, Chem. Commun., 2017, 53, 8604-8607; (d) X. Wang, D. Baiyil and X. Li, RSC Adv., 2016, 6, 107233-107238; (e) T. Li, S. Zhang, S. Meng, X. Ye, $\mathrm{X} . \mathrm{Fu}$ and S. Chen, $R S C A d v ., 2017,7,6457-6466$; $(f)$ N. Gogoi, G. Borah, P. K. Gogoi and T. R. Chetia, Chem. Phys. Lett., 2018, 692, 224-231; $(g)$ X. Xiao, C. Zheng, M. Lu, L. Zhang, F. Liu, X. Zuo and J. Nan, Appl. Catal., B, 2018, 228, 142-151; (h) S. Yurdakala, B. S. Tek, Ç. Değirmenci and G. Palmisano, Catal. Today, 2017, 281, 53-59; (i) M. Zhang, Q. Wang, C. Chen, L. Zang, W. Ma and J. Zhao, Angew. Chem., Int. Ed., 2009, 48, 6081-6084; (j) S. Higashimoto, K. Okada, T. Morisugi, M. Azuma, H. Ohue, T.-H. Kim, M. Matsuoka and M. Anpo, Top. Catal., 2010, 53, 578-583; (k) T. W. Goh, C. Xiao, R. V. Maligal-Ganesh, X. Li and W. Huang, Chem. Eng. Sci., 2015, 124, 45-51.

22 (a) A. E. C. Collis and I. T. Horváth, Catal. Sci. Technol., 2011, 1, 912-919; (b) D. T. Genna, A. G. Wong-Foy, A. J. Matzger and M. S. Sanford, J. Am. Chem. Soc., 2013, 135, 10586-10589.

23 (a) K. C. Gupta, A. K. Sutar and C.-C. Lin, Coord. Chem. Rev., 2009, 253, 1926-1946; (b) C. A. McNamara, M. J. Dixon and M. Bradley, Chem. Rev., 2002, 102, 3275-3300; (c) P. Barbaro and F. Liguori, Chem. Rev., 2009, 109, 515-529.

24 R. B. Merrifield, J. Am. Chem. Soc., 1963, 85, $2149-2154$.

25 S. B. Roscoe, C. Gong, J. M. J. Fréchet and J. F. Walzer, J. Polym. Sci., Part A: Polym. Chem., 2000, 38, 2979-2992.

26 G. J.-J. Chen, J. W. McDonald and W. E. Newton, Inorg. Chem., 1976, 15, 2612-2615.

27 J. M. Frechet and C. Schuerch, J. Am. Chem. Soc., 1971, 93, 492-496.

28 (a) B. Yan and M. Guo, J. Photochem. Photobiol., A, 2013, 257, 34-43; (b) L. Sen, W. Kuan, C. K.-C. Alan, Z. Ming, W. Jing, C. Y. Gang, B. YuHua, W. TaiMing and Z. ZhiRen, Sci. China: Chem., 2012, 55, 1134-1139; (c) J.-W. Kim, K.-J. Kim, S. Park, K.-U. Jeong and M.-H. Lee, Bull. Korean Chem. Soc., 2012, 33, 2966-2970.

29 (a) J.-G. Choi and L. T. Thompson, Appl. Surf. Sci., 1996, 93, 143-149; (b) Y. Li, X. Fu, B. Gong, X. Zou, X. Tu and J. Chen, J. Mol. Catal. A: Chem., 2010, 322, 55-62; (c) P.-S. E. Dai and J. H. Lunsford, J. Catal., 1980, 64, 173-183; (d) J. F. Moulder, W. F. Stickle, P. E. Sobol and K. D. Bomben, Handbook of XPS, PerkinElmer Corporation, Eden Prairie, MN, 1992.

30 S. Brunauer, P. H. Emmett and E. Teller, J. Am. Chem. Soc., 1938, 60, 309-319.

31 E. P. Barrett, L. G. Joyner and P. P. Halenda, J. Am. Chem. Soc., 1951, 73, 373-380.

32 (a) J. J. Boruah, S. P. Das, S. R. Ankireddy, S. R. Gogoi and N. S. Islam, Green Chem., 2013, 15, 2944-2959; (b) D. T. Gokak and R. N. Ram, J. Mol. Catal., 1989, 49, 285-298.

33 (a) K. S. W. Sing, D. H. Everett, R. A. W. Haul, L. Moscou, R. A. Pierotti, J. Rouquerol and T. Siemieniewska, Pure Appl. Chem., 1985, 57, 603-619; (b) S. J. Gregg and 
K. S. W. Sing, Adsorption, Surface Area and Porosity, Academic Press, London, 1982.

34 S.-J. Park, D.-I. Seo and C. Nah, J. Colloid Interface Sci., 2002, 251, 225-229.

35 (a) V. B. Valodkar, G. L. Tembe, M. Ravindranathan and H. S. Rama, React. Funct. Polym., 2003, 56, 1-15; (b) V. B. Valodkar, G. L. Tembe, M. Ravindranathan, R. N. Ram and H. S. Rama, J. Mol. Catal. A: Chem., 2003, 202, 47-64.

36 (a) Md. M. Islam, A. S. Roy and Sk. M. Islam, Catal. Lett., 2016, 146, 1128-1138; (b) D. L. Pavia, G. M. Lampman, G. S. Kriz and J. R. Vyvyan, Introduction to Spectroscopy, 5th edn, Cengage Learning, USA, 2015; (c) R. M. Silverstein, F. X. Webster and D. J. Kiemle, Spectrometric Identification of Organic Compounds, John Wiley and Sons, New York, 7th edn, 2005.

37 P. F. Rapheal, E. Manoj and M. R. P. Kurup, Polyhedron, 2007, 26, 818-828.

38 (a) K. Nakamoto, Infrared and Raman Spectra of Inorganic and Co-ordination Compounds, Part B, Wiley and Sons, New York, 5th edn, 1997; (b) K. H. Reddy, M. R. Reddy and K. M. Raju, Indian J. Chem., 1999, 38A, 299-302; (c) B. S. Garg, M. R. P. Kurup, S. K. Jain and Y. K. Bhoon, Transition Met. Chem., 1991, 16, 111-113.

39 (a) M. R. Maurya, S. Sikarwar, T. Joseph, P. Manikandan and S. B. Halligudi, React. Funct. Polym., 2005, 63, 71-83; (b) M. R. Maurya, U. Kumar and P. Manikandan, Dalton Trans., 2006, 3561-3575.

40 (a) B. Altava, M. I. Burguete, E. Garcia-Verdugo, S. V. Luis and M. J. Vincent, Tetrahedron, 2001, 57, 8675-8683; (b) D. LinVen, N. B. Colthup, W. G. Fateley and J. G. Grasselli, The Handbook of Infrared and Raman Characteristic Frequencies of the Organic Molecules, Academic, London, 1991; (c) J. R. Ferraro and K. Nakamoto, Introductory Raman Spectroscopy, Academic, London, 1994; (d) M. J. Pelletier, Analytical Applications of Raman Spectroscopy, Blackwell, Oxford, 1999.
41 (a) F. E. Kuhn, M. Groarke, E. Bencze, E. Herdtweck, A. Prazeres, A. M. Santos, M. J. Calhorda, C. C. Romao, I. S. Goncalves, A. D. Lopes and M. Pillinger, Chem. - Eur. J., 2002, 8, 2370-2383; (b) L. J. Willis, T. M. Loehr, K. F. Miller, A. E. Bruce and E. I. Stiefel, Inorg. Chem., 1986, 25, 4289-4293.

42 (a) A. O. Sobola, G. M. Watkins and B. V. Brecht, S. Afr. J. Chem., 2014, 67, 45-51; (b) A. O. Sobola, G. M. Watkins and B. V. Brecht, J. Serb. Chem. Soc., 2018, 83, 1-12.

43 (a) G. Lisa, E. Avram, G. Paduraru, M. Irimia, N. Hurduc and N. Aelenei, Polym. Degrad. Stab., 2003, 82, 73-79; (b) W. Mo, H. Liu, H. Xiong, M. Li and G. Li, Appl. Catal., A, 2007, 333, 172-176.

44 J. J. Boruah, D. Kalita, S. P. Das, S. Paul and N. S. Islam, Inorg. Chem., 2011, 50, 8046-8062.

45 (a) M. Uyanik, D. Suzuki, T. Yasui and K. Ishihara, Angew. Chem., 2011, 123, 5443-5446; (b) M. Uyanik and K. Ishihara, ChemCatChem, 2012, 4, 177-185.

46 (a) K. Amakawa, Y. V. Kolen'ko, A. Villa, M. E. Schuster, L.-I. Csepei, G. Weinberg, S. Wrabetz, R. N. d'Alnoncourt, F. Girgsdies, L. Prati, R. Schlögl and A. Trunschke, ACS Catal., 2013, 3, 1103-1113; (b) C. J. Carrasco, F. Montilla, E. Álvarez, C. Mealli, G. Mancac and A. Galindo, Dalton Trans., 2014, 43, 13711-13730; (c) B. Trost and Y. Masuyam, Isr. J. Chem., 1984, 24, 134-143; (d) M. R. Maurya, M. Kumar and U. Kumar, J. Mol. Catal. A: Chem., 2007, 273, 133-143; (e) M. R. Maurya, A. K. Chandrakar and S. Chand, J. Mol. Catal. A: Chem., 2007, 274, 192-201.

47 (a) C. Hansch, A. Leo and R. W. Taft, Chem. Rev., 1991, 91, 165-195; (b) H. Szatylowicz, O. A. Stasyuk and T. M. Krygowski, Adv. Heterocycl. Chem., 2015, 116, 137192; (c) H. H. Jaffe and G. O. Doak, J. Am. Chem. Soc., 1955, 77, 4441-4444.

48 (a) R. Malakooti and A. Feghhi, New J. Chem., 2017, 41, 34053413; (b) A. V. Biradar, M. K. Dongare and S. B. Umbarkar, Tetrahedron Lett., 2009, 50, 2885-2888; (c) S. Campestrini and F. D. Furia, Tetrahedron, 1994, 50, 5119-5130. 